\title{
"LOZA QUEBRADA" PROCEDENTE DE LA CAPILLA DEL COLEGIO-UNIVERSIDAD DE SANTA MARÍA DE JESÚS (SEVILLA)
}

\author{
POTTERY FROM THE CHAPEL OF THE COLEGIO-UNIVERSIDAD \\ DE SANTA MARÍA DE JESÚS (SEVILLA)
}

\author{
por \\ ALFONSO PLEGUEZUELO \\ ANTONIO LIBRERO \\ MARÍA ESPINOSA \\ PEDRO MORA
}

RESUMEN En este artículo se describe un conjunto de más 300 piezas de cerámica común de producción defectuosa, actualmente depositadas en el Real Alcázar de Sevilla, y procedente del relleno de la bóveda del presbiterio de la Capilla del Colegio de Santa María de Jesús en la misma ciudad. Su fecha de fabricación e instalación puede ser fijada entre 1503 y 1506 a través de datos documentales publicados. La totalidad de objetos, obedece a 50 tipos formales distintos de los que 30 eran hasta ahora inéditos. La publicación en esta misma revista de trabajos de los que éste pudiera resultar complementario, añade ahora valor a la divulgación de estos datos. La variedad tipológica, la posibilidad de conocer su cronología de producción -en un momento histórico clave para Sevilla y su amplio radio de acción-, su buen estado de conservación y su probable origen local, convierten este conjunto en una colección de especial interés arqueológico aunque su extracción en la década de 1970 no fuera realizada lamentablemente con el rigor que hoy hubiera sido efectuada tal operación.

\footnotetext{
ABSTRACT In this paper, a group of more than 300 ceramic artifacts of defective manufacture that are presently in the Real Alcázar of Seville, is described. The coarsewares come from the filling of the voult of the presbitery of the chapel of Santa María de Jesús College in the same city. The date of manufacture and setting can be fixed between 1503 and 1506 by means of documentary data allready published. The objects follow 50 different formal patterns from which 30 of them are now published for the first time. This paper might complement other works published in this issue and this makes more valuable the spreading of this data. The typological variety, the possibility to know the chronology of their manufacture - a crucial historic period of Seville and a wide area of influence- its good conditions and its probable local origin, make this group a collection of special archaeological interest although their taking out in the 70's was unfortunatelly, not carried out with the scientific accuracy that would be necessary nowadays.
} 
El conocimiento de la cerámica común sevillana del período medieval y postmedieval es aún muy deficitario aunque ello no constituye, lamentablemente, una excepción en el panorama nacional ${ }^{1}$. No obstante, la situación del caso sevillano ha ido cambiando por fortuna en los últimos años gracias a las aportaciones recientes de material debidas al auge general que la arqueología urbana y monumental ha experimentado en nuestro país ${ }^{2}$. Ello ha supuesto que algunos arqueólogos sevillanos hayan empezado a estudiar con rigor y a publicar colecciones de objetos obtenidos en excavaciones sistemáticas tanto de yacimientos del subsuelo como, sobre todo, de bóvedas rellenas con material de cocciones defectuosas, material que denominamos, siguiendo los documentos de la época, "loza quebrada". No obstante, a pesar del esfuerzo realizado en los últimos años en este terreno, sería deseable que la recopilación de información descriptiva a partir de colecciones significativas aumentase y alcanzara un grado suficiente que permitiera obtener conclusiones de orden más profundo.

Escasas noticias documentales de archivos sevillanos referidas a este concreto método de relleno de los espacios interiores de las bóvedas, han sido publicadas por Gestoso en relación a la catedral. (GESTOSO 1904: 370 y ss.)

El número de piezas de cerámica común sevillana conservadas en colecciones privadas o públicas y procedentes de rellenos de bóvedas o de capas aislantes bajo los pavimentos era hace ya unas décadas relativamente elevado, aunque la carencia de información arqueológica e histórica de que adolecía todo este material reunido hasta ese momento, disminuía y aún disminuye de forma lamentable su valor referencial a la hora de compararlo con materiales aparecidos en nuevas excavaciones. A pesar de ello, fue utilizado como única posibilidad para elaborar una primera y genérica aproximación al tema por uno de autores de este trabajo (PLEGUEZUELO, A. 1993). Como se ha comentado más arriba, en los últimos años se ha incrementado el interés de cierto sector de la arqueología sevillana por este tipo de materiales y la extracción de los mismos se ha ido realizando de forma mucho más sistemática que en el pasado, lo cual ha generado nuevas aportaciones al conocimiento del tema realizadas ya con gran rigor y precisión. (AMORES y CHISVERT 1991).

Nuestro propósito con este pequeño trabajo es el de añadir alguna información más al repertorio de formas publicadas, especialmente el del completo trabajo de Amores y Chisvert referido en la nota anterior y al que haremos continuas alusiones en éste, ya que en él los autores dan a conocer un total de 212 formas procedentes en su mayor parte de conjuntos de relleno bien datados entre mediados del siglo XV y la segunda mitad del siglo XVIII. En el nuestro, el total de tipos formales es de 50, de los que aproximadamente 30 son publicados ahora por primera vez.

Las piezas cerámicas que aquí se dan a conocer, procedentes del presbiterio de la capilla del Colegio de Santa María de Jesús (Lám. 1 Fig 1), forman uno de los primeros conjuntos sevillanos de relleno de bóvedas que fueron extraídos y conservados, aunque no había sido descrito en su conjunto hasta el momento presente.

La iniciativa y la buena disposición de la Dirección de los Reales Alcázares, donde se encuentra la colección en la actualidad, ha permitido realizar este trabajo de simple registro gráfico comentado someramente $^{3}$. Las operaciones básicas de siglado, fichado, toma de fotos y realización de dibujos se hicieron

1. Para una visión actualizada del estado de conocimientos de este tema puede consultarse GERRARD, Ch.; GUTIÉRREZ, A. y VINCE, A. (1995).

2. Para un balance muy clarificador sobre la situación actual de la arqueología española y sobre los sectores de la misma que se han interesado por el mundo medieval y moderno véase AMORES, F. (1997).

3. Consciente del valor de esta colección, su actual conservador, Don José María Cabezas, solicitó en 1991 la colaboración de dos jóvenes historiadores del arte (Librero y Espinosa) para realizar el inventario de dicho conjunto bajo la orientación de uno de nosotros (Pleguezuelo). Los tres autores del mismo quieren expresar su agradecimiento a la Dirección del monumento, tanto por la iniciativa tomada en este asunto como por las facilidades continuas prestadas a nuestro trabajo durante su realización. 
inmediatamente con la intención de que, a nivel de documentación, la imagen obtenida de la colección fuese al menos la del estado en que se encontraba en la fecha inicial de este trabajo (1994) ${ }^{4}$.

\section{EL EDIFICIO}

La historia del edificio del que procede esta colección de artefactos está relativamente bien documentada y suministra una información útil para contextualizar estos objetos.

El Colegio de Santa María de Jesús es, en cierta forma, el origen institucional de la actual Universidad de Sevilla. Fue fundado por Maese Rodrigo Fernández de Santaella, quien emprende esta iniciativa en los primeros años del siglo XVI ${ }^{5}$. En 1502 los Reyes Católicos habían concedido una Real Cédula por la que autorizaban al Cabildo Municipal de Sevilla el establecimiento de un Estudio General. Amparado en este privilegio, Maese Rodrigo solicitó al Papa Julio II la concesión de una bula pontificia para fundar un Colegio que se dedicara preferentemente a estudios de Teología y Derecho Canónico. La primera Bula llega a concederse el 12 de julio de 1505 y se verá confirmada más tarde por una segunda expedida en 1508 . Pero Maese Rodrigo no esperó tanto y el 13 de junio de 1503 adquiere el solar donde pensaba construir su fundación. (HAZAÑAS Y LA RÚA 1909: 59).

Las obras debieron empezar con rapidez y la capilla es precisamente de las primeras partes del conjunto que se concluyen. Maese Rodrigo declara el 17 de Mayo de 1506: “... que la Dicha iglesia ya estava edificada del todo...". (GESTOSO 1892: 31). En efecto, ese mismo día el obispo Fray Reginaldo Romero la bendice y celebra en ella la primera misa. (HAZAÑAS Y LA RÚA 1909: 74). A pesar de la claridad del comentario precedente, otra declaración del fundador hace pensar que algunos trabajos no estructurales aún estaban por concluir. Concretamente el 12 de enero de 1509 Maese Rodrigo, en su segundo testamento, hace algunos comentarios referidos a “...la capilla del Colegio de Santa María de Jesús, que agora fago...”. (GESTOSO 1892: 29). Otras partes del mismo documento clarifican esta aparente contradicción y dejan claro que quedaban por terminar sólo algunas labores ornamentales de la capilla y otras zonas importantes del resto. Todo ello se estaba edificando según el proyecto del cantero Antón Ruiz, proyecto cuyas condiciones de obra, según dispone Maese Rodrigo, deberían ser respetadas por sus albaceas testamentarios encargados de gestionar la continuación de las mismas después de su muerte ${ }^{6}$. Cinco años más tarde (1514), el maestro albañil Martín Sánchez, se compromete a ejecutar la delicada obra de albañilería de la portada de la capilla. (ANGULO ÍNIIGUEZ 1932: 137). En 1516-17 debían estar concluidos todos los trabajos ya que ese año comienza la actividad docente. La capilla que se construye en los primeros años del siglo XVI obedece a un planteamiento arquitectónico muy sencillo (Fig. 2). Está compuesta por un presbiterio de planta cuadrada cubierto con bóveda nervada de crucería y una minúscula nave de planta rectangular cubierta por una armadura de carpintería?.

A principios del siglo XVII se efectuó en la capilla una obra de importancia que no afectó a la estructura del presbiterio ni al muro de la fachada del hastial, pero que dejó huellas evidentes en los muros laterales de la nave los cuales probablemente fueron rehechos por completo (Fig. 3). Estas obras de principios del siglo XVII deben estar conectadas con los avatares históricos que atraviesa el Colegio por esas fechas.

4. Los dibujos de las piezas fueron realizados por el licenciado en Bellas Artes Pedro Mora Frutos con cargo al grupo de investigación de la Universidad de Sevilla "GRUPO LARAÑA" financiado por el Plan Andaluz de Investigación de la Junta de Andalucía.

5. Sobre esta figura puede consultarse el completo estudio de Joaquín HAZAÑAS Y LA RUA (1909).

6. HAZAÑAS Y LA RÚA (1909: 118). La obra de cantería de la capilla es de importancia ya que incluye la bóveda del presbiterio, la ventana gótica del mismo, y la propia portada del Colegio, hoy reubicada en el compás del Monasterio sevillano de Santa Clara.

7. Nuestro agradecimiento a Don Rafael Manzano Martos, autor del proyecto de restauración, quien nos facilitó amablemente la planimetría original del edificio que nos ha servido de base para realizar los croquis que aquí se incluyen de la arquitectura de la capilla. 
A principios del seiscientos, la competencia ejercida por otras instituciones educativas locales sitúa al Colegio en una posición de inferioridad y ello impulsa a sus responsables a emprender una operación general de renovación. El 20 de enero de 1617 se publican nuevos estatutos que reafirman su título de Colegio Mayor, equiparable a los otros seis que existían en Castilla. En 1622 adopta un nuevo protector, el Conde Duque de Olivares, con la finalidad, tal vez, de situarse bajo el patronazgo del propio rey a través de su valido más influyente y a pesar de que ello implicaba perder parte de su autonomía anterior ${ }^{8}$. Este nombramiento será refrendado por el propio Felipe IV en 1623, cuando impone también la demostración de "limpieza de sangre" como condición para ingresar en la institución. En 1624 el Rey visita la ciudad y recibe a los representantes del Colegio con los honores de Estudio General. Nueve años después, en 1633, vuelve a confirmar su categoría de Colegio Mayor en un documento oficial. Sólo en este ambiente renovador se explicaría una reforma importante como la reconstrucción de los muros de la nave y, probablemente, la ejecución de una nueva armadura de carpintería de lo blanco ${ }^{9}$.

El colegio seguiría una historia posterior azarosa hasta que, a excepción de su capilla, fuera demolido hacia 1909 con motivo de las obras de ensanche que dieron lugar a la actual Avenida de la Constitución. (HAZAÑAS Y LA RÚA 1909: 120).

\section{DATACIÓN Y VALOR DEL MATERIAL CERÁMICO}

En resumen, el presbiterio de la capilla debió construirse entre 1503 y 1506 y es posible, aunque no seguro, que fuese reparado parcialmente cuando la nave se renueva hacia 1620-25. El primero de los hitos citados sería, hipotéticamente, la clave para datar el material que se usó en el relleno aligerado de la bóveda de nervadura que cubre el primero de los elementos (Fig. 1). Dicha bóveda estaría trasdosada al exterior, como era habitual en esos momentos, por una solería de ladrillo o de azulejo que formaría las pendientes necesarias para que el agua de lluvia se evacuara con facilidad por las gárgolas. Las citadas obras de renovación en la nave, realizadas a principios del siglo XVII, no implican forzosamente que el presbiterio se viera afectado por ellas pero no resultaría extraño tampoco que se hicieran reparaciones en una cubierta que ya tenía más de un siglo de antigüedad. El análisis tipológico de los materiales contenidos en el interior de la bóveda podría corresponderse, en principio, con esta hipótesis ya que la inmensa mayoría de los objetos responden con seguridad a tipos datables hacia 1500 y sólo una mínima proporción de ellos podría corresponder a modelos propios de principios del siglo XVII. Ningún objeto de la colección parece datar de forma clara de momento diferente a los dos citados.

8. En ese mismo año se coloca una lápida en la fachada del edificio con el siguiente texto: "Reinando D. Felipe IV Nuestro Señor muy poderoso y alto Señor mando / esta muy noble y muy leal ciudad / de Sevilla renovar estas letras / siendo Asistente D. Pedro Deza del Aguila, Conde de la Fuente / y Diputado / D. Justo Vicentelo de Leca, Conde de / Cantillana, caballero de la Orden de Santiago / Alcalde Mayor de Sevilla / Gentilhombre de Voca del Rey Nuestro Señor/. Por acuerdo capitular de 21 de Noviembre de 1622 años / ante / Francisco de Torres Correa, familiar de esta Santa Inquisición / escribano del Cabildo y Regimiento, / por D. Rodrigo de Torre y Vera, escribano (?) Mayor de el". Esta lápida se mantuvo en el edificio hasta que en 1971, con motivo de las obras de restauración mencionadas, se deposita en el Museo Arqueológico de Sevilla.

9. La compartimentación de la superficie exterior del muro meridional en pilastras sin capiteles y las ventanas rectangulares con abras hacia el exterior, propias de las formas arquitectónicas empleadas en Sevilla a principios del seiscientos, evidencian materialmente esta renovación parcial del edificio. Estas formas recuerdan a las empleadas por el arquitecto Vermondo Resta a quien tal vez haya que atribuir esta intervención. Resta fue desde 1607 hasta 1625 Maestro Mayor de los Reales Alcázares cuyo terreno se extendía hasta los solares contiguos al colegio y era, además, el arquitecto personal del Don Gaspar de Guzmán, CondeDuque de Olivares, en esos años Alcaide de los Reales Alcázares y nuevo patrono del Colegio desde 1621. 
Los valores habituales de este tipo de material de relleno ligero para bóvedas han sido ya citados en otros trabajos y de tales valores participan también los objetos que forman este conjunto. Entre los más notables estarían el haberse conservado completos, el hecho de constituir con certeza producciones locales, el formar colecciones más o menos cerradas y el poseer cronologías de producción y no de uso. Con respecto a la hipótesis a veces sugerida de que cada conjunto de bóveda proceda de un mismo alfar, es una afirmación que vemos más arriesgada ya que en ocasiones, incluso para bóvedas de tamaño no excesivamente grande, vemos probable que se acudiera a más de un proveedor. Por ejemplo, en el caso que aquí analizamos se perciben, en objetos del mismo uso, diferencias tipológicas excesivamente marcadas como para suponerlos fabricados por el mismo alfarero. Esta hipotética procedencia diversificada se ha confirmado sobre todo en los conjuntos de bóvedas más tempranos del siglo XVI, como el que aquí presentamos, dada la producción limitada de los alfareros de tradición medieval, frente a la semiindustrial de los botijeros fabricantes de contenedores comerciales que aumentan paulatinamente el volumen de producción a partir de principios del siglo XVI y que permitiría compras masivas desde mediados del quinientos en adelante.

El material que aquí se aporta hubiera sido un conjunto de valor arqueológico muy superior al que realmente posee si su extracción hubiera sido realizada de forma totalmente controlada y si su almacenamiento hubiera garantizado la conservación inalterada del conjunto de objetos recuperados. Lamentablemente, en la fecha en que esta operación se realizó con motivo de unas obras de restauración promovidas por el Ministerio de Cultura (1971), la arqueología urbana y monumental se encontraba en una situación bastante más inmadura que la actual y casi hemos de agradecer que en aquella ocasión los responsables de la obra mostraran la sensibilidad suficiente como para extraer el material y almacenarlo en algunas dependencias de los Reales Alcázares, lugar donde aún se encuentra a falta de un destino museístico más adecuado. Por añadidura, la carencia de las necesarias condiciones de almacenamiento y seguridad en que los objetos se han mantenido, ha facilitado que el conjunto original de artefactos extraídos haya ido mermándose en el transcurso de los años. En conclusión, nos tememos que no están aquí representadas todas las cerámicas que formaban el conjunto original aunque sí pensamos, por el contrario, que pertenecen a él todas las que han llegado a nosotros como integrantes del mismo.

A pesar de estas limitaciones, la aparente coherencia de la colección, el número elevado de formas diferentes registradas, el buen estado de conservación de la mayor parte de ellas y, sobre todo, el valor que le concede el hecho de estar indirectamente datadas con cierta precisión, convierten este conjunto en una colección que consideramos de suficiente interés como para que sea dada a conocer a los especialistas. Ello no es obstáculo para que sea preciso tomar con cierta cautela las afirmaciones aquí vertidas y para que en trabajos ulteriores hechos con más rigor, convenga verificar la información que aquí se ofrece.

\section{DESCRIPCIÓN DE LAS CERÁMICAS}

En la descripción y tratamiento de los objetos citados a continuación seguiremos criterios muy similares a los adoptados en el mencionado trabajo de Amores y Chisvert con el fin de que este material, en la medida de lo posible, pueda ser complemento del anterior, cuyos criterios de ordenación compartimos de forma general.

No procederemos, pues, a realizar descripciones formales sistemáticas que nos parecen innecesarias desde el momento en que los objetos se reproducen dibujados con cierta precisión. Tampoco describimos de manera detallada las pastas cerámicas con que están realizados ya que nuestra formación de historiadores no nos permite abordar tal descripción petrológica con el rigor que actualmente ha alcanzado esta clase de operaciones. En líneas generales, corresponden a cinco de los tipos de pastas más frecuentemente empleados 
en las cerámicas comunes sevillanas ${ }^{10}$. Las pastas de estos objetos de alfarería se agruparían, pues, de la siguiente manera:

Pasta 1.- Pasta clara de tono amarillento-ocre con la que están fabricados objetos de paredes de grosor fino aunque la superficie de los mismos suele presentar una textura uniformemente rugosa. Con ella se fabrican dolias, cantimploras de uso comercial, lebrillos medianos, algunas orzas, algunos cántaros y los cangilones. Esta pasta parece ser muy frecuente en cerámicas comunes desde el siglo XIV y va desapareciendo desde principios del siglo XVI para ser sustituida paulatinamente por la que se cita a continuación.

Pasta 2.- A veces de tono pajizo en superficie pero tendente al rosado en el corte. Es una pasta menos decantada que la anterior. Suele emplearse en artefactos algo más pesados y de paredes más gruesas como botijas comerciales, caños, bacines y toda clase de objetos de uso doméstico.

Pasta 3.- El tercer tipo de pasta es el característico de las piezas fabricadas para ser usadas en contacto con el fuego y su color es rojo vivo. A veces se cubre parcialmente con baño de barniz plumbífero y se usa para ollas y cazuelas.

Pasta 4.- De color rojo oscuro y textura refinada empleada en la fabricación de objetos para refrescar el agua como jarros de mesa y cantimploras no comerciales.

Pasta 5.- Pasta de "alcarracero" o barro muy blanquecino, depurado, calcáreo, salino y poroso, apto para piezas de paredes muy delgadas y destinadas a refrescar agua por sudoración, tales como jarritas, tallas y alcarrazas.

Las pastas 3, 4 y 5 son de caracteres visibles fáciles de reconocer. Por el contrario, las 1 y 2 aunque son en la mayor parte de la veces identificables a simple vista, en otras ocasiones se confunden puesto que la tonalidad rosa de la segunda depende frecuentemente de condiciones de cocción y no de los elementos minerales que la componen. Por añadidura, entre estos dos tipos hay otros intermedios imposibles de distinguir sin pruebas analíticas, visiones microscópicas o secciones delgadas.

En cuanto al criterio de agrupación seguido para ordenar los objetos, pensamos que cualquiera que sea el adoptado siempre presentará contradicciones, lo que nos ha llevado a elegir el que personal y subjetivamente nos parecía menos inconveniente y más adecuado al material " . La división por ámbito funcional es tal vez la más práctica aunque es insegura ya que se desconoce el uso de algunas formas y tendemos a adjudicarles funciones por comparación con objetos de forma similar que han llegado hasta tiempos recientes. No obstante, seguiremos, en principio, este primer criterio para establecer grupos como: transporte, almacenamiento, mesa, cocina, higiene, uso agrícola y uso arquitectónico. Dentro de algunos de ellos (almacenamiento y transporte) podría establecerse una subdivisión según el artefacto fuese usado en el entorno doméstico o en un ambiente comercial. Pero la pertenencia a uno de estos dos ámbitos, dato que casi siempre se mueve en el terreno de las conjeturas, no se traduce siempre en una diferencia de formas. En cualquier caso, los objetos que se describen a continuación, al limitarse a un conjunto concreto, tampoco permiten mostrar un cuadro clasificatorio de validez general que incluya todos los posibles objetos cerámicos. Si se hacen estos razonamientos de método es sólo por la disparidad de criterios y de nomenclaturas que reflejan los trabajos de los especialistas y que pensamos, sería deseable aminorar en la medida de lo posible por la facilidad que ello comportaría en el intercambio de informaciones y en las referencias que establecemos habitualmente al aplicar el método comparativo.

10. En este conjunto están ausentes las piezas de vajilla de mesa fabricadas con la tradicional pasta calcárea crema-amarillenta.

11. Usaremos la nomenclatura actual para designar los objetos a excepción de los casos en que el uso del término histórico esté perfectamente comprobado. 


\section{TRANSPORTE}

\subsection{DOLIAS (Figs. 4-6) (Pasta 1)}

Es probable que estos objetos sean los primeros contenedores comerciales sevillanos cristianos aunque parecen haber sido usados sólo para el comercio europeo ya que ningún ejemplo ha sido detectado, hasta ahora, en yacimientos americanos. Por el contrario han aparecido en otros edificios sevillanos (PLEGUEZUELO 1993: Fig. 3 n$^{\circ} 12$ y AMORES y CHISVERT 1993: Figs, 33, 3435 y 38), en Valencia (AMIGUES et al. 1991), en Southampton, (PLATT y COLEMAN 1975: 1291, 1308; HURST 1977: Fig. 33, 55 -56) y en Serravezza (Toscana) (FRANCOVICH Y GELICHI 1986: 306-309, 311, Fig. 5.2, tav. XI). Los ejemplares más antiguos parecen datar del siglo XIV y el tipo se mantendría en uso, como se comprueba por los ejemplares aquí descritos, hasta principios del siglo XVI.

Varias de estas piezas presentan, sobre la arista de los hombros, las marcas dejadas por una cuerda, lo que ha llevado a pensar a algunos autores que tal marca es la huella de unión de dos supuestas partes del objeto. Por el contrario, pensamos que estas piezas fueron elevadas en el torno de manera unitaria. La cuerda se ataría alrededor de la pieza en su diámetro máximo para evitar que las paredes se abriesen con la manipulación, transporte en fresco o con el peso de otras piezas soportado durante su cocción, momento en que la cuerda se quemaría con el fuego del horno dejando impresa su huella sobre el barro. Este procedimiento se utilizaba en otros artefactos de gran tamaño que corrían riesgos similares de reventarse o de que sus paredes se desplomasen como, por ejemplo, los lebrillos, que muestran una huella similar en su labio exterior.

En la colección de la capilla de Maese Rodrigo, hemos identificado un total de trece dolias con rasgos comunes como el tipo de pasta clara con leve tendencia al rosado, el grosor de las paredes, extremadamente sutil en relación con el tamaño que alcanzan los objetos y la carencia generalizada de cubierta vítrea. No obstante estos rasgos comunes, se perciben tres tipos diferenciados levemente por matices formales como el perfil de las piezas y especialmente sus bocas.

Tipo A: (Fig. 4) con seis ejemplares.

Tipo B: (Fig. 5) con cinco ejemplares.

Tipo C: (Fig. 6) con dos ejemplares y un tamaño algo inferior a los anteriores.

\subsection{CANTIMPLORAS COMERCIALES Y DOMÉSTICAS (Figs. 7-16).}

Este es un tipo de recipiente que ofrece aún numerosas dudas en cuanto a su denominación, a sus usos originales y a las motivaciones de algunos de sus rasgos formales.

En cuanto al primer aspecto, Goggin lo denominó "Early Type" dentro del grupo de las "olive jars" (GOGGIN 1960: 8); posteriormente fue llamado "botija perulera" (AMORES y CHISVERT 1991: 163-176); más tarde, uno de nosotros lanzó la hipótesis de que estos objetos podrían ser los que en la documentación comercial de la primera mitad del siglo XVI son citados como "jarras" y nosotros puntualizamos como "jarras comerciales" para distinguirlas de las "jarras domésticas" (PLEGUEZUELO-SÁNCHEZ 1993: 1092), hipótesis de denominación que hemos mantenido en un trabajo posterior (PLEGUEZUELO 1993: 48). Casi al mismo tiempo, el objeto era publicado por Amores y Chisvert con la denominación de "Cantimplora" (AMORES y CHISVERT 1993: 282), aplicándole correctamente el término moderno con que son denominados los objetos con esta forma en el bajo valle del Guadalquivir. Aunque en esa zona y en tiempos recientes acostumbran a ser de pequeño tamaño, se conocen, por el contrario, versiones de gran dimensión pertenecientes a períodos históricos anteriores y también se fabricaban recientemente en el valle alto del mismo río donde se las llama simplemente "botijas", denominación ésta que no aconsejamos por considerarla 
más confusa para nosotros ya que la aplicamos ahora a otras formas sin asas. En este artículo, hemos decidido, siguiendo a los autores citados, llamarla "cantimplora" por ser tal vez la denominación con menos inconvenientes y también por no confundir más la situación taxonómica en que este artefacto se encontraba en la bibliografía al uso ${ }^{12}$.

La característica más original de este objeto es su método de fabricación ya que su cuerpo se forma como una esfera torneada y completamente cerrada a la que se abre, a punta de navaja, un orificio lateral junto al que se insertan el cuello, previamente torneado aparte, y las dos asas laterales. Este método hace que, cuando el objeto adopta su posición normal de uso, las estrías del torneado no quedan horizontales, como es habitual, sino verticales. La razón de tan infrecuente rasgo, podría residir en que es la única forma de fabricar un objeto a torno dándole más panza por una cara que por la otra, es decir, con un perfil disimétrico, rasgo que se presenta muy frecuentemente en los ejemplares de tamaño mediano y pequeño y que se le da al objeto para favorecer la comodidad de su transporte, adherido al costado de una persona o de una caballería, o de su colocación, colgado de un clavo en la pared o en el tronco de un árbol.

Es muy probable que este objeto, de origen cristiano, fuese ideado primitivamente como contenedor de agua aunque, por extensión, puede haber servido también como envase comercial de otros líquidos e incluso sólidos, especialmente alguna de sus variantes. Es sintomático, en este sentido, que hayan sido los ejemplares vidriados y a veces con boca ancha los que hayan sido registrados en yacimientos ultramarinos. Los tipos de cuellos y bocas de la generalidad de estos objetos, con paralelos muy estrechos con los cántaros, parecen confirmar este uso fundamentalmente asociado al agua. Sabemos que las cantimploras estaban, al igual que las botijas comerciales, revestidas de esparto tejido con el fin de servir de protección contra los golpes.

Debieron hacerse simultáneamente en Sevilla con diferentes matices formales como se comprueba por los ejemplares que aquí se presentan. Algunas de estas variantes se asemejan a otros publicados procedentes de alfares no sevillanos, sino de la provincia (AMORES-CHISVERT 1993: Fig. 45,46, 47 y 51) o incluso portugueses (TORRES 1990: 135, fig. 11; 1991: 193, fig. 19).

Amores y Chisvert han establecido para las cantimploras tres tipos según su tamaño aunque perciben dificultades para precisarlos por la falta de regularidad de los mismos (AMORES-CHISVERT 1993: 282). Nosotros hemos confirmado en esta colección la existencia de los tres tamaños básicos (diámetro aproximado 15,25 y $35 \mathrm{cms}$. respectivamente) correspondientes probablemente a los que cita la documentación como "jarra de arroba" (12 litros), "de media arroba" (6 litros) y "de azumbre" (2 litros) (PLEGUEZUELO y SÁNCHEZ 1993: 1093). También hemos constatado la citada falta de homogeneidad de sus capacidades, lo que nos hace pensar en un uso preferente no comercial para la mayor parte de ellos. En cualquier caso, vemos preferible establecer los tipos de este conjunto atendiendo a la forma, igual que se suele hacer con otros objetos como las botijas comerciales o los cántaros.

Según este criterio formal, podríamos distinguir básicamente tres subtipos aunque en esta colección sólo detectamos dos de ellos:

Tipo A: (Figs. 7-15) (Pasta 1). Es la forma más frecuente en yacimientos sevillanos, especialmente en los rellenos de bóvedas (AMORES y CHISVERT 1993: Figs. 39, 40, 41, 43, 45, 46, 47, 48 y 49; PLEGUEZUELO 1993: Fig. 13). A este tipo pertenecen veintiún ejemplares de esta colección. No ha sido registrado en los yacimientos americanos aunque sí en los europeos (HURST 1977: 98-101) y tal vez sea el tipo más antiguo de los tres. Por la pasta de tono pajizo, el torneado de paredes finas y los tipos de cuello, dan la impre-

12. No empleamos para estos objetos la denominación de "botijo plano" que se les da en Aragón porque ni son planos siempre ni la palabra botijo se aplica en Andalucía occidental a objetos que no sean de base estable y para beber agua a chorro. Tampoco usamos el término "barril" ya que en Andalucía esta palabra se reserva a formas cilindriodes similares al tonel hecho con duelas de madera de roble. 
sión de ser objetos realizados por cantareros. La mayor parte de las cantimploras de esta colección responden precisamente a este primer tipo y a los tres tamaños básicos citados. Se detecta una cierta tendencia a que los tamaños mayores correspondan a las formas más esféricas en tanto que los menores se acercan a formas más aplanadas sin llegar a las versiones estrechas y aristadas como las del tipo C que describiremos después. También dependiendo del tamaño, se percibe que las formas grandes suelen presentar, vistas de perfil, simetría en las dos caras en tanto que las pequeñas poseen en ocasiones tratamientos formales diferentes entre ambas. En este último caso, una cara es más aplanada y otra rehundida y con pezón central resaltado.

Tipo B: (ningún ejemplar en esta colección) (Pasta 2). Se caracteriza este grupo por presentar una pasta más grosera que el tipo A y por ser el único de los tres del que conocemos ejemplares vidriados. Dan la impresión de ser fabricación menos fina que la cantarería. Este tipo fue el primero en ser descrito al ser ampliamente documentado en yacimientos americanos (GOGGIN 1960 y 1968: 228; DEAGAN 1987:33) y posteriormente en yacimientos sevillanos (AMORES y CHISVERT 1991: Lám. 1-3; AMORES y CHISVERT 1993, Figs. 42, 44 y 50).

Tipo C: (Fig. 16) (Pasta 4). Forman este grupo ejemplares siempre de tamaño pequeño, realizados en pasta roja oscura, bastante depurada y con forma particularmente facetada, aristada y plana para facilitar su transporte cuando van colgadas al hombro. Igual que las formas medianas del tipo A, presentan dos caras diferentes; una más lisa y la opuesta rehundida y con pezón. Es, de los tres tipos, el más parecido a las cantimploras modernas aunque, por lo que se aprecia aquí, ya se fabricaban a principios del siglo XVI. También debieron ser producidas en otros centros alfareros del área sevillana (AMORES-CHISVERT 1993: Fig. 51). A este grupo pertenecen dos ejemplares de un mismo tipo (Fig. 16) de la colección de la capilla de Maese Rodrigo. La pasta roja vincularía este tipo a una labor de cerámica para agua con raíces locales importantes pero con una gran tradición en Portugal (louça vermelha) y en la Extremadura española (Salvatierra, Ceclavín etc.).

\subsection{BOTIJAS COMERCIALES. (Figs. 17-19) (Pasta 2).}

Este apartado, de enorme importancia histórica, es el único que plantea en esta colección algunas reflexiones sobre la coherencia general de la misma. La clasificación y datación de las botijas, realizada en principio por la bibliografía americana a partir de las colecciones ultramarinas (GOGGIN 1960; LISTER 1981; MARKEN 1994), ha sido recientemente revisada y parcialmente modificada por autores españoles (AMORES y CHISVERT 1993). Partiendo de los grupos descritos por éstos últimos, en la colección de la capilla de Maese Rodrigo se detectan ejemplares pertenecientes a los tipos A y B.

Tipo A: (Fig. 17) Referido a una botija de forma ovoide y tamaño grande, la bibliografía americana hacía comenzar su cronología hacia 1580 en tanto que el trabajo de los arqueólogos sevillanos la adelantan hasta fines del siglo XV. No obstante, la forma de la boca de los objetos de este tipo en la capilla de Maese Rodrigo no se asocia, en principio, a los ejemplares más tempranos publicados en el citado trabajo sino a los de la segunda mitad del siglo XVI e inicios del XVII (MARKEN 1994: 61-72). De los cuarenta y nueve ejemplares de este tipo existentes en esta colección, dos muestran una marca impresa sobre el amplio labio regruesado. Una de ellas está compuesta por un anagrama formado por las letras mayúsculas $\mathrm{A}, \mathrm{V}, \mathrm{P}$ y $\mathrm{E}$ y la otra representa una granada, emblema que, por cierto, fue especialmente frecuente hacia 1500 .

Tipo B: Plantean una problemática similar (AMORES y CHISVERT 1993: 284). El tipo se caracteriza por su forma esférica o esferoide pero, a pesar de pertenecer por la forma de su cuerpo a dicho tipo, el ejemplar de esta colección muestra también rasgos evidentes de diferencia en las bocas y en las bases de ambos con lo que su datación podría ser similar al del tipo anterior; es decir, principios del siglo XVII. 
Tipo B-1: (Fig. 18) El único ejemplar de este tipo perteneciente a la colección posee una boca idéntica al tipo A descrito antes aunque su base es cóncava, extraña a los ejemplares publicados como tempranos y más frecuente en los datables en el siglo XVII. (AMORES y CHISVERT 1993: figs. 81-83).

Tipo B-2: (Fig. 19) Sería el representado por cuarenta y nueve ejemplares. Sus rasgos son diferentes al tipo anterior ya que su labio carece de arista superior y su base es convexa. Sus paralelos con piezas publicadas con cronología cierta asociarían también este subtipo a un período tardío del siglo XVII con lo cual se convertiría este tipo en el único que no responde a la datación planteada "a priori". Resultan de especial interés en un ejemplar de este tipo, los trazos sinuosos hechos en almagra roja sobre la superficie de la botija, asociable a las marcas comerciales con las que se pretendía facilitar su identificación en el puerto de destino.

\subsection{CÁNTARAS DE DOBLE ASA (Figs. 20-22)}

En la colección de la capilla de Maese Rodrigo, aparecen tres variantes diferentes con un ejemplar cada una. Todas ellas con doble asa, cuello cilíndrico, boca ancha y base cóncava.

Tipo A: (Fig. 20) (Pasta 2) Una pieza similar al único ejemplar de este tipo ha sido descrito anteriormente y citado como "cántara de ordeño o destilación" (AMORES y CHISVERT 1993: Fig. 23). A pesar de su parecido con algunas modernas cántaras de aluminio para el transporte de dicho líquido, los antiguos recipientes para recoger la leche del ordeño, como las "gamellas" o las "colodras", solían estar vidriadas y tener una forma muy diferente con base muy amplia para evitar que el recipiente se volcase por las coces del animal y labio muy amplio y exvasado para recoger el chorro de leche que a veces tiene direcciones imprevisibles y un amplio radio de dispersión. El parecido de estas piezas con otras similares recuperadas en la Cartuja de Jerez (LISTER y LISTER 1981: Fig. 5; 1987: Fig. 94 E) es evidente como han constatado Amores y Chisvert (1993: 278).

Tipo B: (Fig. 21) (Pasta 1) Al segundo tipo pertenece una sola pieza y es un objeto diferente, más esbelto y asociable a los cántaros de esta misma colección aunque con el asa doble.

Tipo C: (Fig. 22) El único ejemplar del tercer tipo de cántara se distingue por carecer de cuello y acercarse a la forma de las orzas. Sus rasgos la relacionan concretamente con los cántaros del Tipo $\mathrm{H}$, descrito más adelante.

\subsection{CÁNTAROS (Figs. 23-32)}

Objeto de uso doméstico destinado al transporte del agua de la fuente pública hasta la casa o del pozo a la cantarera y, de forma excepcional, usado también en el transporte comercial marítimo. Se registran en este conjunto los dos tamaños habituales que se comercializaban: el cántaro "de azacán" o de aguador, con capacidad de una arroba ( 12 litros) y el de media arroba (6 litros). También se aprecian ejemplares de tamaños intermedios que se aproximan a los dos anteriores. Contamos con ocho variantes según la forma, alcanzándose en este apartado la mayor variedad tipológica del conjunto.

Dos de esos ocho tipos cuentan con la versión de arroba y de media arroba, los otros seis, sólo están presentes en uno de los dos tamaños.

Tipo A. (Fig. 23) Un sólo ejemplar. Base plana y labio fino con resalte interior para servir de apoyo a la cobertera.

Tipo B. (Fig. 24) Un sólo ejemplar. Base plana y labio moldurado en cinta. 
Tipo C. (Fig. 25) (Pasta 2) Veintidós ejemplares de los cuales diecisiete son grandes, tres medianos y dos pequeños. Uno de ellos muestra impresa en la base del asa, la imagen simplificada de la Giralda, lograda por la presión de un cuño. Esta marca era el control municipal sobre el correcto tamaño y capacidad del cántaro para ser usado por un aguador y ya ha sido detectada en otras piezas sevillanas publicadas, tal vez procedentes del mismo alfar (PLEGUEZUELO 1993: Fig. 7) y relacionable con uno de los alfareros que suministran cántaros para la capilla de la Virgen de la Antigua en la Catedral (AMORES y CHISVERT 1993: Fig. 95).

Tipo D: (Fig. 26). Un ejemplar. Base plana y cuello bulboso. Guarda relación con piezas similares procedentes de San Isidoro del Campo (1468-1492) y del Claustro de Legos de la Cartuja de las Cuevas (AMORES Y CHISVERT 1993: Fig. 94).

Tipo E: (Figs. 27-28). Siete ejemplares grandes y dos medianos. Es llamativo su cuello cilíndrico, su labio fino y las estrías marcadas de su torneado a la altura de la panza para evitar que resbale durante su manipulación.

Tipo F: (Fig. 29). Un ejemplar. Labio sin moldurar y ligeramente exvasado.

Tipo G: (Fig. 30). Un ejemplar. Se diferencia del anterior por su perfil especialmente panzudo y su boca particularmente ancha.

Tipo H: (Figs. 31-32). Es el tipo más abundante con treintaiún ejemplares de tamaño grande y ocho de tamaño mediano. Base cóncava y labio moldurado en cinta plana. Uno de los ejemplares de este tipo muestra una marca incisa en forma de aspa situada en los hombros y cuyo significado desconocemos.

Las diferencias entre los ocho tipos son de matices pero, en general, este conjunto comporta varias novedades respecto de los tipos ya publicados. Llama la atención, el hecho de que sólo tres de las ocho variantes posean base plana (Figs. 23, 24, 25 y 26). Los demás la presenta cóncava (Figs. 27, 28, 29, 30, 31 y 32 ). Este último tipo de base coincide con un ejemplar publicado procedente de Carmona y datado en la segunda mitad del siglo XVII (AMORES y CHISVERT 1993: Fig. 99) pero el resto de los rasgos de los ocho tipos de cántaros, tales como pasta, delgadez de paredes, perfil esbelto, bases estrechas, tipo de asas de cinta, cuellos altos, bocas de labio fino etc, obedecen, en general, a tipos mucho más tempranos datables con seguridad a principios del siglo XVI.

\section{ALMACENAMIENTO}

\subsection{ORZAS (Figs. 33-38)}

Contiene la colección cuatro tipos de orzas diferentes en cuanto a su forma. De hecho, morfológicamente son piezas muy dispares:

Tipo A: (Fig. 33) (Pasta 1) La primera, de la que hay dieciocho ejemplares, tiene forma bulbosa con labio muy exvasado hacia el exterior dispuesto para recibir una cobertera. Es una forma no registrada hasta ahora y parece una tinajilla en tamaño muy reducido.

Tipo B: (Fig. 34) (Pasta 1) La segunda, con sólo un ejemplar, es una orza de tamaño muy grande. Si no fuese por el leve grosor de sus paredes y porque está realizada a torno, podría considerarse una tinaja. Su base y su boca son amplias; su labio, muy plano preparado para encajar una gran cobertera y sobre sus hombros, aparece una decoración realizada a peine de cinco púas formando bandas rectas, sinuosas, en zig-zag y a trazos cortos. Un ejemplar muy similar fue registrado en los rellenos de la bóveda de la Capilla de la Antigua (AMORES y CHISVERT 1993: Fig. 140).

Tipo C: (Fig. 35) (Pasta 1) La tercera, con dos ejemplares, tiene forma de pequeño tibor de corto cuello vertical. Un ejemplar similar apareció también en la capilla de la Virgen de la Antigua de la Catedral (AMORES Y CHISVERT 1993: Fig. 141). 
Tipo D: (Fig. 36) (Pasta 1) La cuarta, con un ejemplar, es casi cilíndrica, con forma similar a los bacines pero muy amplio, con labio más estrecho y carente de asas. También de este tipo fue registrado un ejemplar en la citada capilla de la Virgen de la Antigua (AMORES y CHISVERT 1993: Fig. 128).

Tipo E: (Fig. 37) (Pasta 1) Se caracteriza por la base y boca muy amplias y las dos asas enfrentadas. Tipos similares de alfarería reciente reciben el nombre de "asados" y se usan para almacenar pan o conservas cárnicas. Se trata de un tipo de orza con ejemplares similares publicados (AMORES y CHISVERT 1993: Fig. 135 y PLEGUEZUELO 1993: Fig. 4) aunque, a diferencia de aquellos, el ejemplar aquí descrito está vidriado en color melado.

Tipo F: (Fig. 38) Tipo muy simple de orza sin asas pero con labio horizontal rehundido para recibir cobertera.

\subsection{TARROS O BOTES (Figs. 39-40) (Pasta 2)}

Contamos con dos modelos de gran parecido en forma y cubierta melada interior y derrame exterior que no alcanza la totalidad de la pieza.

Tipo A. (Fig. 39) Forma cilíndrica con estrechamiento bajo la carena superior curva.

Tipo B. (Fig. 40) Cuerpo muy cilíndrico con carenas apenas perceptibles.

La base plana de ambos tipos se convertirá con el tiempo en uno de los rasgos más peculiares de los tarros sevillanos de botica o de uso doméstico, rasgo propio de la alfarería que pasará luego a los botes de loza fina. Una pieza de base plana, similar a una de estas fue registrada en el Monasterio de San Isidoro del Campo (AMORES y CHISVERT 1993: Fig. 31). No obstante, también hay tarros con bases anulares como el que procede precisamente de esta colección y fue publicado anteriormente (AMORES y CHISVERT 1993: Fig. 32).

\section{MESA}

\subsection{JARRITAS (Fig. 41) (Pasta 5)}

Sólo conservamos dos ejemplares de un mismo un modelo de jarrita (Fig. 41), de pequeñas dimensiones. La pasta es de color blanquecino propia de labor de alcarracería y las paredes muy delgadas. Aunque estos objetos llevaban frecuentemente decoración incisa o abullonada (AMORES y CHISVERT 1993: Figs. 183-188), los dos ejemplares aquí hallados carecen de ornamentación. Este tipo de objetos es probable derivación de una forma de tradición musulmana que se colocaba bajo la vertedera de los reposaderos de tinajas donde se recogía el agua filtrada a través de las paredes de tales contenedores. También se solían colocar tapando la boca de los cántaros para que sirvieran de cobertera y al mismo tiempo se pudiera beber de ellas. Recibían el nombre de tallas, las más pequeñas y estrechas, y alcarrazas, más amplias y frecuentemente provistas de tapadera.

\subsection{JARROS (Fig. 42-55)}

Distinguimos los jarros de las jarras por el criterio convencional del número de asas. En este epígrafe van incluidos todos los tamaños de jarros ya que la habitual distinción entre jarros y jarritos nos resulta aquí compleja de aplicar al haberse detectado más de un tamaño intermedio entre el mayor y el menor. De hecho, entre las piezas de esta colección distinguimos cuatro tamaños diferentes con independencia de los diversos tipos que corresponden a sus matices formales. 
Tipo A: (Figs. 42-51) (Pasta 2) Veintiún ejemplares de la colección pertenecen a este tipo que muestra cuatro tamaños. Tiene una forma robusta relativamente cercana a la de los cántaros aunque con base plana más amplia, asa más grande, cuello de paredes convexas y boca ancha. La mayor parte de ellos, salvo un ejemplar (Fig. 46), están vidriados con barniz melado muy espeso y brillante y con algún chorreón accidental de vedrío verde (Fig. 42). Poseen paralelos muy estrechos con ejemplares registrados en el Monasterio de San Isidoro del Campo y en la Cartuja de las Cuevas, Sala Capitular y celdas Q y R (AMORES y CHISVERT 1993: Figs. 164, 165, 166, 167, 179 y 182). Uno de los ejemplares pequeños (Fig. 51) presenta un perfil bulboso diferente al resto pero su pasta y su cubierta lo asocian a los demás de este tipo. Es curioso constatar la frecuencia con que estos ejemplares pequeños poseen una base regruesada en su borde externo, rasgo que no hemos percibido en los ejemplares de tamaños medianos y mayores.

Tipo B: (Fig. 52) (Pasta 1) Cuenta con dos piezas que están realizadas en pasta muy clara, no lleva cubierta y su perfil tiende a la forma cilíndrica al marcar poco la transición entre la leve panza y el ancho cuello.

Tipo C: (Figs. 53-55) (Pasta 4) Cuatro ejemplares forman este tipo que se diferencia no sólo por unas formas suaves y bases algo convexas que impiden un asiento perfecto sino, sobre todo, por la pasta de color rojo oscuro y la carencia de vedrío. Por dicha pasta se relacionaría con las cantimploras del Tipo C (Fig. 13).

\section{COCINA}

\subsection{ANAFE (Fig. 56) (Pasta 2)}

Este objeto, derivación de otros tipos de tradición musulmana, se presenta aquí con la forma que mantendrá durante toda la Edad Moderna. Ejemplares similares han sido ya publicados anteriormente (AMORES y CHISVERT 1993: Fig. 203 y PLEGUEZUELO 1993: Fig. 34). El de la capilla de Maese Rodrigo, ha perdido el cenicero inferior aunque conserva íntegro el brasero superior.

\subsection{OLLAS (Figs. 57-58 (Pasta 3)}

En esta colección de piezas sólo hemos podido distinguir dos tipos de ollas, cada una de ellas con una morfología diferente.

Tipo A: (Fig. 57) Es un tipo de olla clásico aunque carece de cubierta vítrea. Su exterior está ennegrecido por efecto del fuego ya que, a diferencia de los demás objetos, parece haber sido usada.

Tipo B: (Fig. 58) Fabricada también en pasta roja, presenta la peculiaridad, no muy frecuente, de poseer cuatro asas en lugar de las dos habituales. Su pasta y su base algo convexa elimina la posibilidad de que se trate de una orza.

\subsection{MORTEROS (Fig. 59) (Pasta 2)}

Tenemos dos variantes de morteros, aunque levemente diferenciadas. Ambos, fabricados con pasta rosácea en corte y pajiza en superficie, presentan las características propias de estas piezas, es decir, paredes muy gruesas, sobre todo en la base, y gran abertura de la boca en cuyo labio se percibe un canalillo vertedor.

Tipo A: (Fig. 59) Se han conservado catorce piezas.

Tipo B: Sólo se conserva un ejemplar. 


\subsection{REDOMAS O ALCUZAS (Figs. 60-61) (Pasta 2)}

Objeto usado en la cocina para verter aceite sobre los alimentos. También fueron usados eventualmente como envase comercial. Entre los ejemplares registrados, se detectan los dos tamaños más usuales. Diez ejemplares son más pequeños y tres mayores aunque no están aquí todos los varios formatos que se usaban en la época. Ambos tamaños pertenecen, no obstante, al mismo tipo y tal vez al mismo alfar. Los vidriados son de tono melado tendente en ocasiones hacia el verdoso.

\section{HIGIENE}

\subsection{BACINES (Figs. 62-66)}

Estos objetos de uso muy generalizado en la Edad Media, forman en esta colección un grupo muy coherente en el que se perciben sólo dos tipos diferentes que se distinguen por su perfil, su pasta y su cubierta.

Tipo A: (Figs. 62-65) (Pasta 2) Es el tipo más abundante aquí con ocho ejemplares correspondientes a cuatro tamaños diferentes. Muestran amplia base, paredes convergentes y amplio labio inclinado. Todos los ejemplares de este tipo llevan baño de vedrío melado interior y en madil exterior. Se percibe por ciertos chorreones de vedrío verde recibidos por goteo de otros objetos en el horno, que algunos de ellos se cocían en posición lateral. Ejemplares muy similares a este tipo son los que se hallaron en la Cartuja de las Cuevas (celdas O y P y Capilla de Santa Catalina), en el Monasterio de San Isidoro del Campo y la Capilla de la Virgen de la Antigua (AMORES y CHISVERT 1993: Figs. 112, 114 y 115).

Tipo B: (Fig. 66) (Pasta 4) Un ejemplar, hecho en pasta roja, con perfil troncocónico invertido y carente de cubierta vidriada representa un tipo diferente a los anteriores.

\section{USO AGRÍCOLA}

\subsection{CANGILONES O ARCADUCES (Figs. 67-69) (Pasta 1)}

Los detalles formales de los seis ejemplares registrados no permiten apenas diferenciar tipos sino sólo tres tamaños de perfiles muy semejantes, especialmente, los dos más pequeños. Las aristas acusadas para marcar el labio y los dos estrangulamientos para alojar las cuerdas de asidero a la noria parecen indicar tipos tempranos aunque la evolución de este objeto es casi imperceptible. Los ejemplares publicados más parecidos proceden de la Cartuja de las Cuevas y, curiosamente, de la iglesia de San Juan de Marchena (AMORES y CHISVERT 1993: Figs. 11 y 17), lo que podría indicar que la alfarería de tal localidad trabajaba en una tradición muy semejante a la sevillana.

\section{CERÁMICA ARQUITECTÓNICA}

\subsection{CAÑOS O ATANORES (Figs. 70-72) (Pasta 2)}

Aunque sabemos por documentación que se usaban tanto para conducir aguas en los edificios como para el riego de las huertas, no tenemos indicadores para diferenciar el uso arquitectónico respecto del frutícola ni tampoco para identificar las diferentes denominaciones que se les daba en el siglo XVI, tales como "caño de la reina", caño naranjero", "caño limonero" etc. (TASSA 1627: 75). Tres son los formatos registrados en esta colección entre los siete ejemplares. 
8. PIEZA SIN CLASIFICAR (Fig. 73) (Pasta 2)

Objeto en forma de pera, sin aparentes restos de asas y cuya apariencia completa desconocemos.

\section{CONCLUSIONES}

El porcentaje que el total de piezas de esta colección supone respecto de todas las registradas en los grandes conjuntos ya publicados por Amores y Chisvert en su repetidamente citado trabajo, es muy modesto pero la considerable variedad de tipos que incluye aumenta notablemente su interés.

El total de objetos contabilizados en esta colección en el momento en que procedimos a realizar su inventario fue de 325. Esta cifra total podría ser dividida en dos grupos de piezas si nos atenemos a la datación de sus respectivos tipos formales. Uno estaría compuesto por los 226 objetos que responden a 39 tipos diferentes y que serían datables con seguridad en los primeros años del siglo XVI y el otro estaría compuesto por los 99 ejemplares que suman los 3 tipos de botijas comerciales que hemos visto con cronología algo dudosa entre inicios del siglo XVI o principios del siglo XVII.

Del total de 42 tipos formales diferentes registrados, aproximadamente unos 30 no tienen paralelos exactos con los publicados ${ }^{13}$. El resto de las piezas muestran en general una relación particularmente estrecha con los tipos descritos por Amores y Chisvert. El número de paralelos establecidos entre estos artefactos procedentes de la Capilla de Maese Rodrigo y los de dichas colecciones publicadas, nos ayudan a confirmar recíprocamente la congruencia de todos éstos conjuntos y su cronología aproximada ${ }^{14}$.

Se comprueba que la mayor parte de los tipos que manifiestan paralelos con otros datados, confirman la cronología dada a la inmensa mayoría de estos artefactos en los primeros años del siglo XVI. Únicamente el caso de las botijas comerciales se aparta de esta datación indudable y permite conceder a estos últimos envases una cronología más amplia que iría de las primeras décadas del siglo XVI a las primeras del XVII con paralelos cercanos en los conjuntos del Noviciado de San Luis y de las Atarazanas.

Partiendo de que la cronología de estas dos últimas colecciones citadas parece estar perfectamente documentada y comprobada, las tres hipótesis que se nos ocurren para dar explicación a la aparente contradicción entre estos tipos de botijas y la cronología asignada a todos los demás objetos de la colección de Maese Rodrigo son las siguientes:

1.- Que el conjunto original hubiese sido incrementado recientemente con objetos de otra procedencia. Esta primera hipótesis, en caso de confirmarse, restaría gran valor a la colección pero la vemos bastante

13. El concepto de "paralelo" que empleamos aquí es forzosamente subjetivo y así lo asumimos. Los criterios usados en las operaciones de comparación son básicamente formales sin atender a coincidencias de pastas cerámicas o tamaños de artefactos. Dentro del ámbito estrictamente formal se incluyen rasgos como el grosor de las paredes, el tipo de base, el perfil total o parcial de la pieza, el tipo de boca y, eventualmente, el de asa o de cubierta externa.

14. El número de paralelos entre los objetos de Maese Rodrigo y los demás conjunto estudiados por Amores y Chisvert nos darían el orden siguiente:

$1^{\circ}$.- Monasterio de San Isidoro del Campo. Sala capitular. Circa 1468-1492. (12 casos de semejanza).

$2^{\circ}$. Cartuja de las Cuevas. Celdas O y P del Claustro de los Monjes. Mediados del s. XV. (9 casos).

$3^{\circ}$.- Cartuja de las Cuevas. Capilla de Santa Catalina. Finales del s. XV. (8 casos).

$4^{\circ}$.- Cartuja de las Cuevas. Sala Capitular (finales del s. XV o principios del s. XVI) ( 7 casos).

$5^{\circ}$.- Catedral de Sevilla. Capilla de la Virgen de la Antigua. Año de 1512. (6 casos)

$6^{\circ}$.- Cartuja de las Cuevas. Almacén de legos. Primera mitad del s. XVI. (4 casos).

$7^{\circ}$.- Cartuja de las Cuevas. Celdas Q y R del claustro de los monjes. Siglo XVI. ( 3 casos).

$8^{\circ}$.- Hospital de las Cinco Llagas. Segunda mitad del s. XVI). (1 caso).

$9^{\circ}$.- Antiguo Noviciado de San Luis. Fines del s. XVII e inicios del XVIII. (1 caso).

$10^{\circ}$.- Atarazanas de Sevilla. Mediados del s. XVIII. (1 caso). 
poco probable. Bien es cierto que la garantía de la procedencia de todos los objetos que formaban parte de la colección de la capilla de Maese Rodrigo cuando se ha realizado el trabajo, es relativa y se apoya, en principio, sólo en la información verbal suministrada por los que han sido responsables de su custodia. Ellos nos han asegurado que la totalidad de los artefactos inventariados proceden del mismo lugar aunque el número de objetos llegados al presente se haya visto disminuido por pérdidas sucesivas. Por decirlo de alguna forma, en el conjunto estudiado, son (objetos originales) todos los que están aunque no están todos los que son.

2.- Que la colección de Maese Rodrigo hubiera sufrido alteraciones en época barroca. Esta posibilidad está dentro de las probabilidades si admitimos que las obras de principios del siglo XVII que provocaron la reconstrucción de la nave pudieran haber afectado parcialmente al presbiterio. Pudo en esa ocasión renovarse total o parcialmente la solería de la azotea, ya con dos siglos de antigüedad, y que en la operación se reforzara el relleno con unos pocos objetos cerámicos comprados como desechos a algún botijero activo en ese momento. Ello explicaría la coincidencia entre los episodios de las obras y la cronología asignable a estos objetos y confirmaría también que los rellenos de bóvedas de inicios del siglo XVI son mucho más variados en tipos que los que se realizan a principios del siglo XVII.

3.- Que los tipos formales objeto de estas dudas cronológicas no hayan sido aún suficientemente estudiados y permitan una datación mucho más amplia de la que hasta ahora se les concedía y que arrancaría desde principios del siglo XVI.

Esperamos que esta colección no sea sino un escalón más en el conocimiento de nuestra alfarería histórica y que otros sucesivos trabajos permitan avanzar en este terreno con más firmeza de la que podemos dar hoy a nuestras hipótesis.

\section{BIBLIOGRAFÍA}

AMIGUES, F., CRUSELLES, E., GONZÁLEZ-VILLAESCUSA, R., LERMA, V. (en prensa): “Los envases cerámicos de Paterna-Manises y el comercio bajomedieval". V Colloque International de Céramique Médievale en Méditerranée Occidentale. Rabat, 1991.

AMORES, F. (1997): "La arqueología postmedieval en España. Panorama y perspectivas" en Archeologia postmedievale I, Archeologia postmedievale: l'esperienza europea el Italia. Convegno internazionale di studi (Sassari, 17-20 ottobre 1994) a cura di Marco Milanese. Universitá degli Studi di Sassari: 51-67.

AMORES, F. y CHISVERT, N. (1991): "Interpretación de un grupo de formas de azúcar del siglo XVI en la Cartuja de las Cuevas (Sevilla)", II Seminario Internacional de la Caña de azúcar en el Mediterráneo (Motril, 1990): 163-176.

AMORES, F. y CHISVERT, N. (1993): "Tipología de la cerámica común bajomedieval y moderna sevillana (ss. XV-XVIII): I: La loza quebrada de relleno de bóvedas". Spal 2: 269-325.

ANGULO ÍNIIGUEZ, D. (1932): Arquitectura Mudéjar Sevillana de los siglos XIII, XIV y XV. Sevilla. DEAGAN, K. (1987): Artifacts of the Spanish Colonies of Florida and the Caribbean, 1500-1800. Smithsonian Institution Press. Washington.

FRANCOVICH, R. y GELICHI, S. (1986): "La cerámica spagnola in Toscana nell Bassomedioevo". Segundo Coloquio Internacional de Cerámica Medieval en el Mediterráneo Occidental: 297-313. Madrid.

GERRARD, Ch.; GUTIÉRREZ, A. y VINCE, A. (1995): Spanish Medieval Ceramics in Spain and the British Isles/Cerámica medieval española en España y en las Islas Británicas. BAR International Series. 610. Oxford. 
GESTOSO, J. (1904): Historia de los barros vidriados sevillanos. Sevilla.

(1892): Sevilla, Monumental y Artística. Tomo 3. Sevilla.

GOGGIN, J. (1960): The Spanish Olive Jars. An Introductory Study. Yale University Publications in Anthropology, $\mathrm{n}^{\circ} 62$.

HAZAÑAS Y LA RUA, J. (1909): Maese Rodrigo (1444-1509). Sevilla.

HURST, J. (1977): “Spanish Pottery Imported into Medieval Britain”. Medieval Archaeology 21: 68-105.

LISTER, F. y LISTER, R. (1981): "The recicled Pots and Potsherds of Spain". Historical Archaeology 15: 66-78.

MARKEN, M. (1994): Pottery from Spanish Shipwrecks 1500-1800. University Press of Florida. Gainsville.

PLATT, C. y COLEMAN,-SMITH, R. (1975): Excavations in Medieval Southampton, 1553-1969. Vol. 2, The Finds. Leicester University Press.

PLEGUEZUELO, A. (1993): "Seville Coarsewares, 1300-1650: a Preliminary Typological Survey". Medieval Ceramics 17: 39-50

PLEGUEZUELO, A. y SÁNCHEZ, J.M. (1993): "Envases cerámicos comerciales en el tráfico con América en el siglo XVI: síntesis de un panorama documental" IV Congreso de Arqueología Medieval en España. III: 1091-1097.

TASSA GENERAL DELOS PRECIOS A QUE SE HAN DE VENDER LAS MERCADERIAS EN ESTA CIUDAD DE SEVILLA Y SU TIERRA... (1627): Mns. Biblioteca de la Universidad de Sevilla.

TORRES, C. (1990): "Un forno cerâmico dos seculos XV y XVI na cintura industrial de Lisboa". Four de potiers et "testares". Médievaux en Mediterranée Occidentale. Publication de la Casa Velázquez, Série Archéologie, XIII: 131-142. Madrid. 


\section{SECCION A'B}
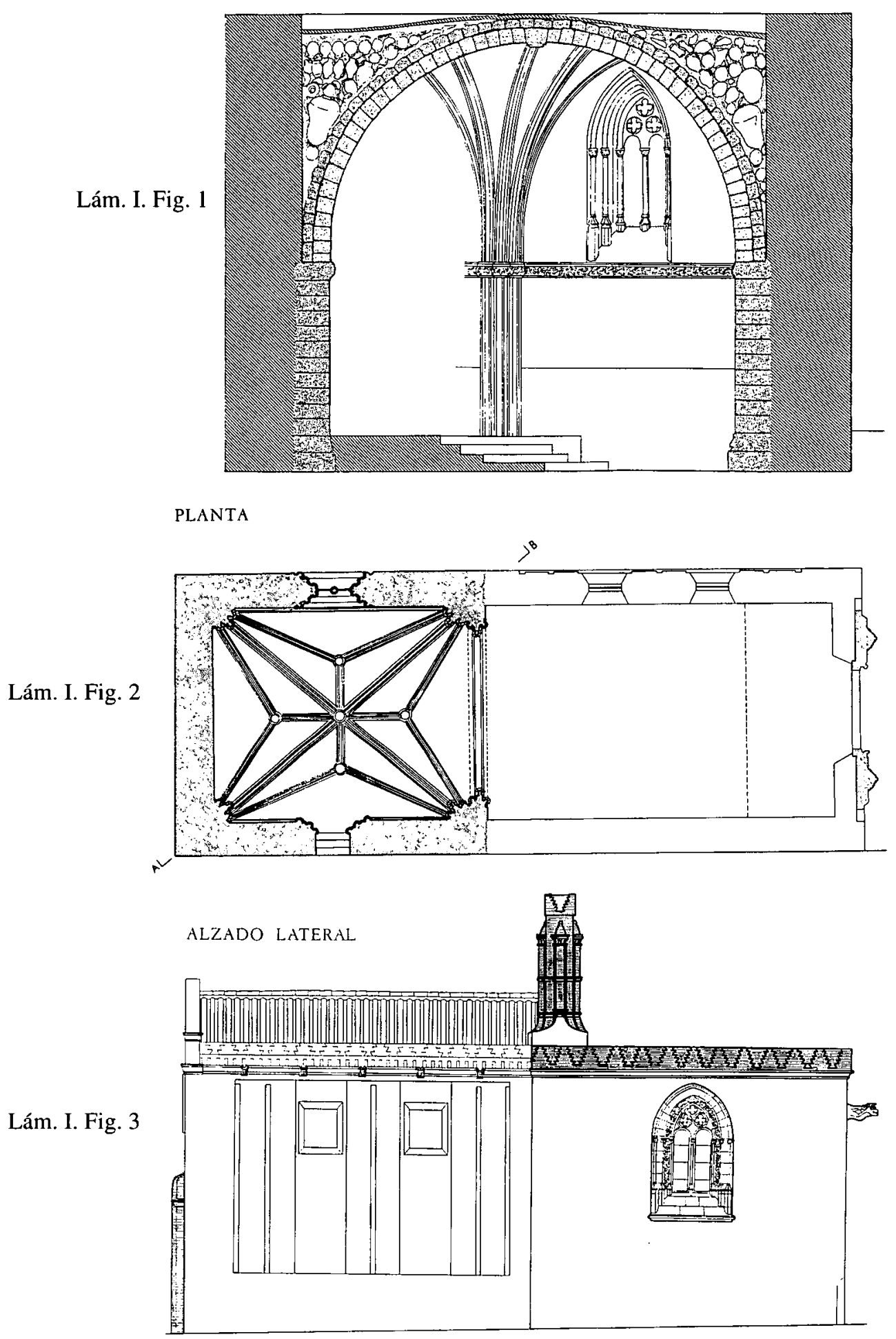


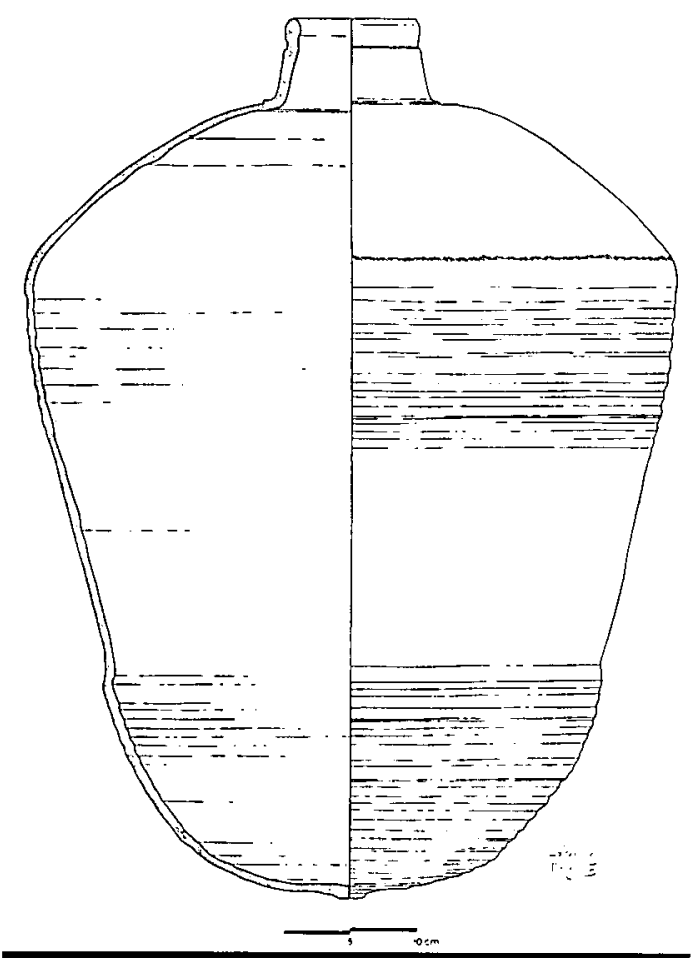

Lám. II. Fig. 5

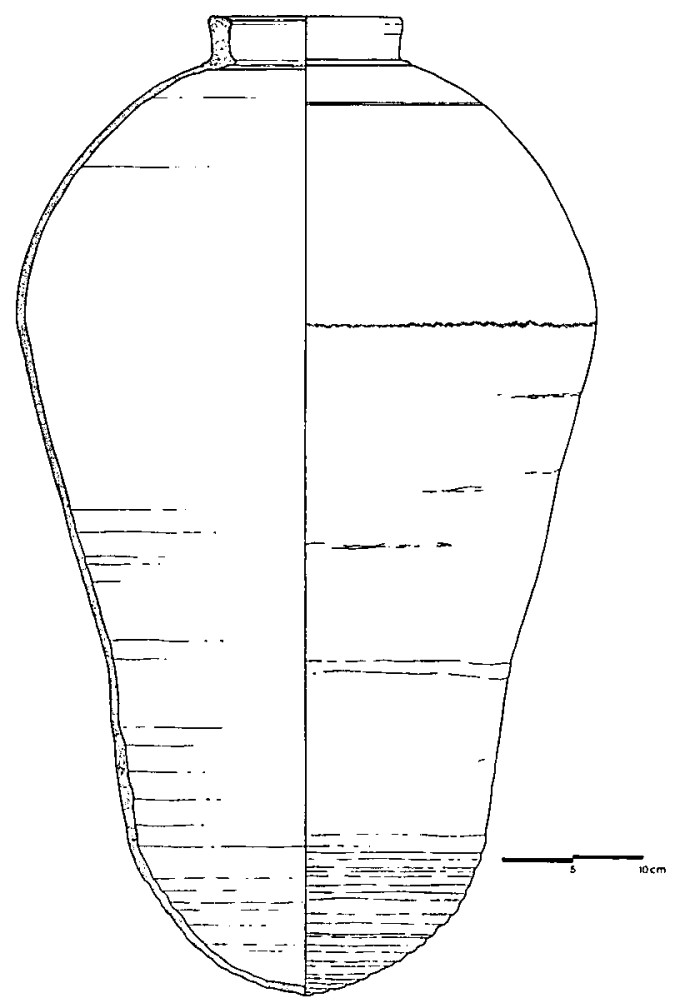

Lám. II. Fig. 4

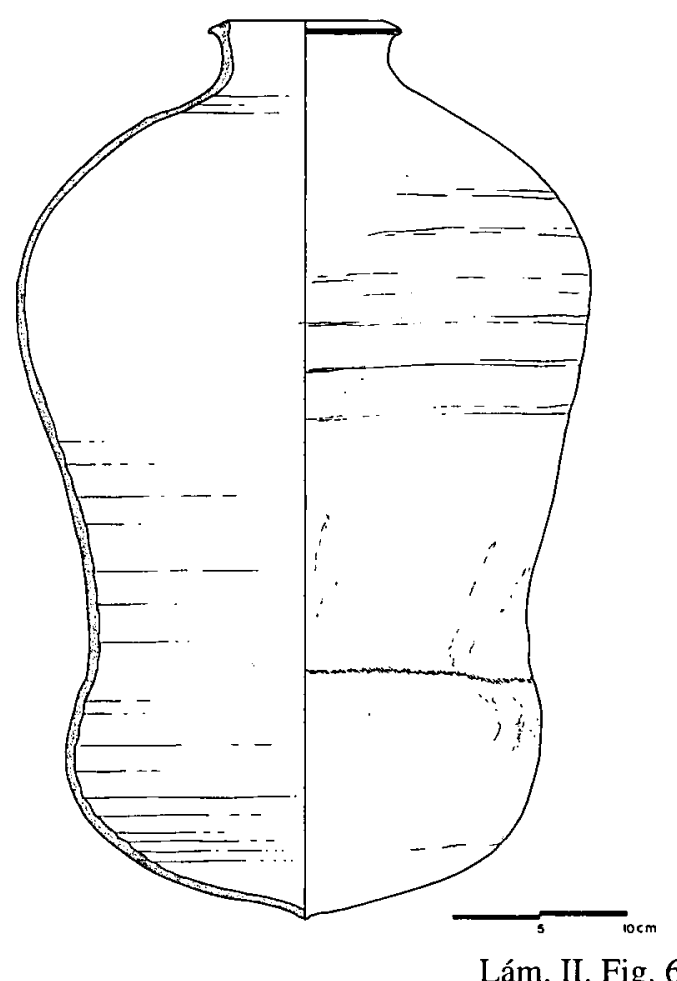

Lám. II. Fig. 6 

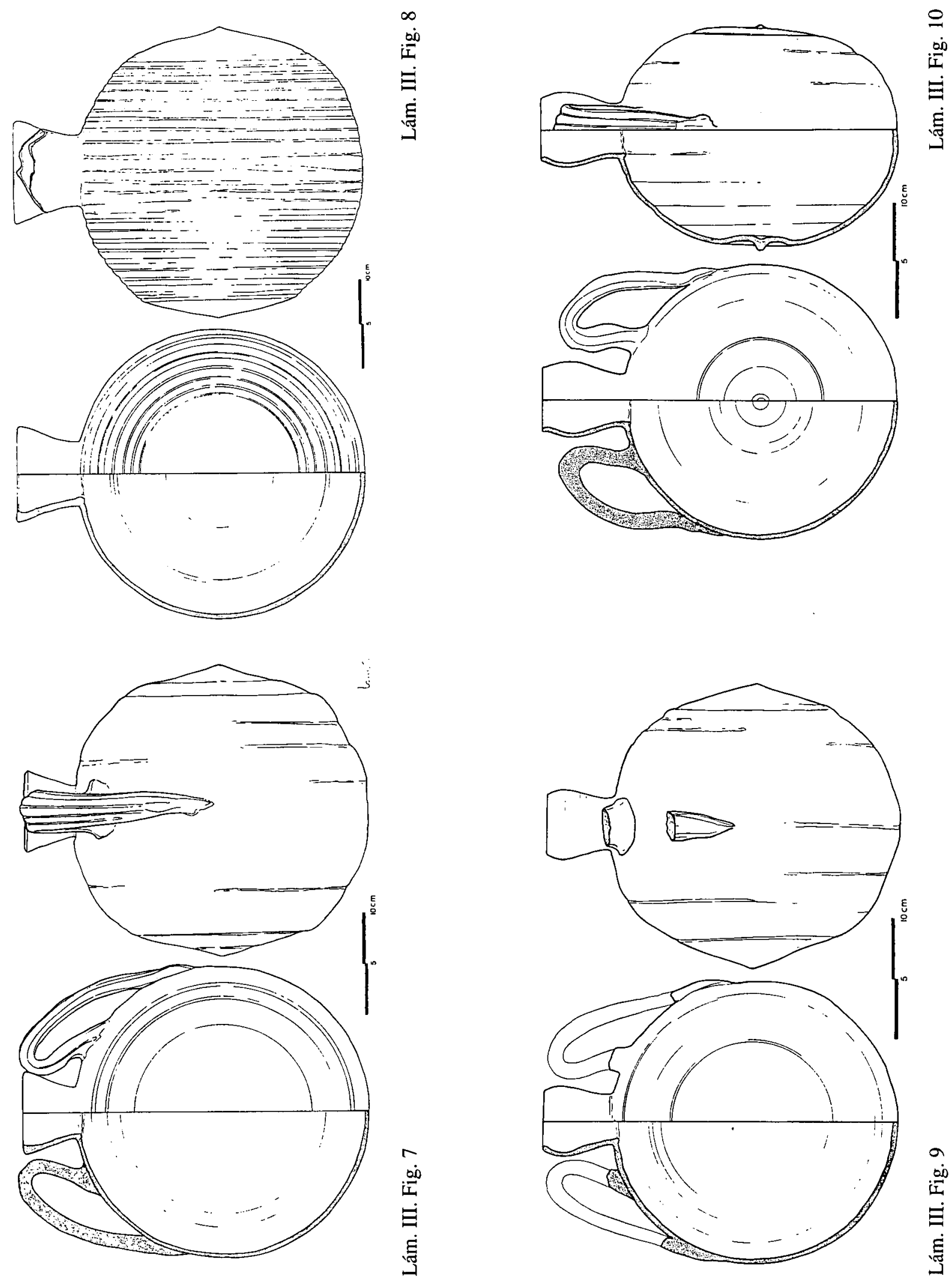

ISSN: 1133-4525 ISSN-e: 2255-3924 http://dx.doi.org/10.12795/spal.1999.i8.14 
“LOZA QUEBRADA" PROCEDENTE DE LA CAPILLA DEL COLEGIO-UNIVERSIDAD DE SANTA MARÍA DE JESÚS... 283

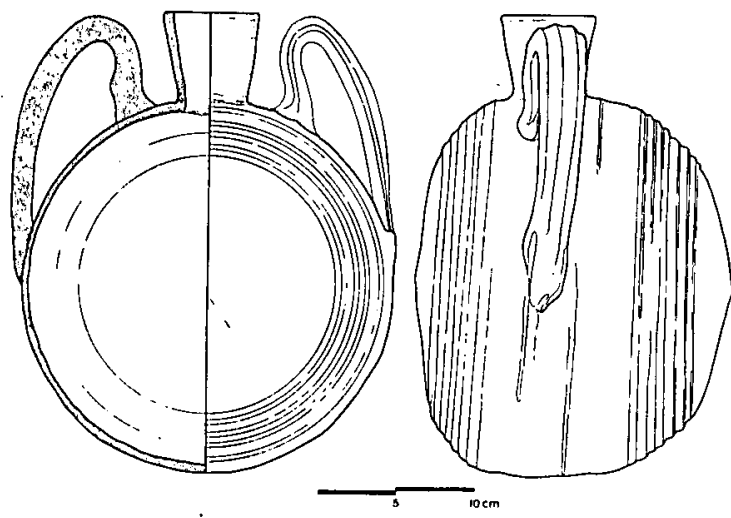

Lám. IV. Fig. 11

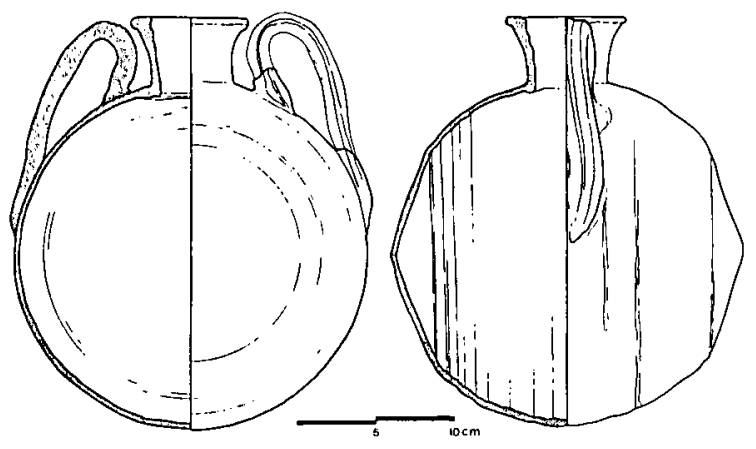

Lám. IV. Fig. 13

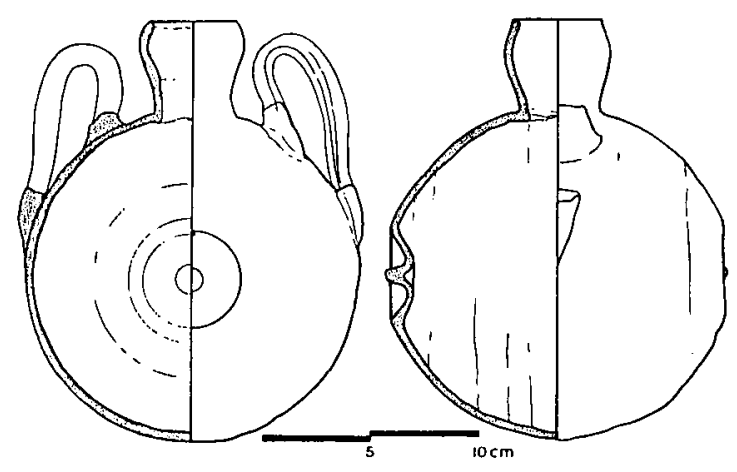

Lám. IV. Fig. 15

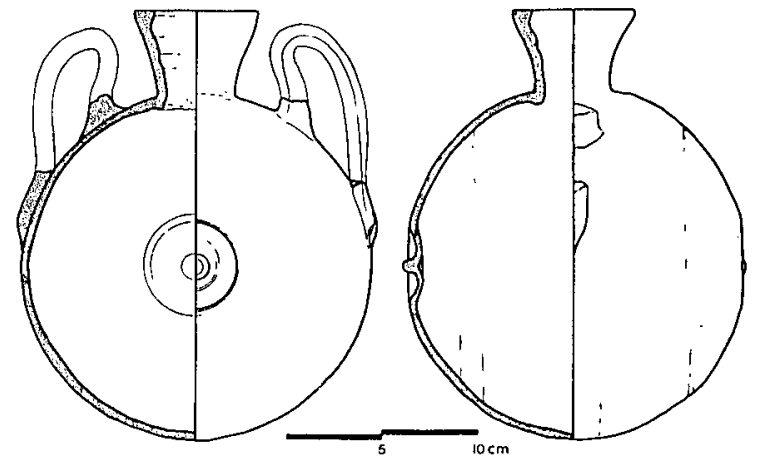

Lám. IV. Fig. 12

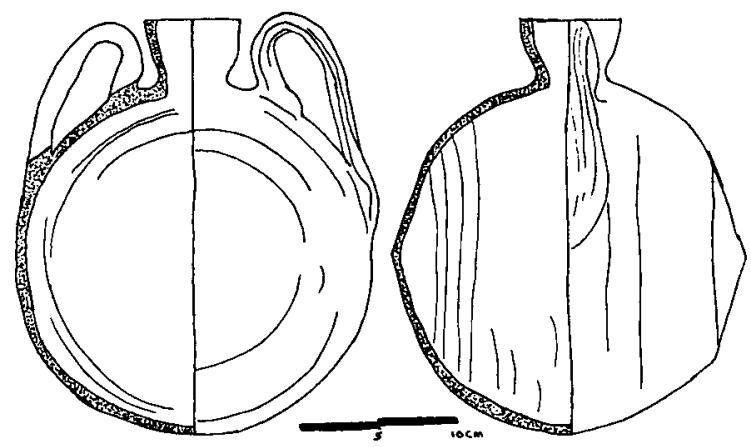

Lám. IV. Fig. 14

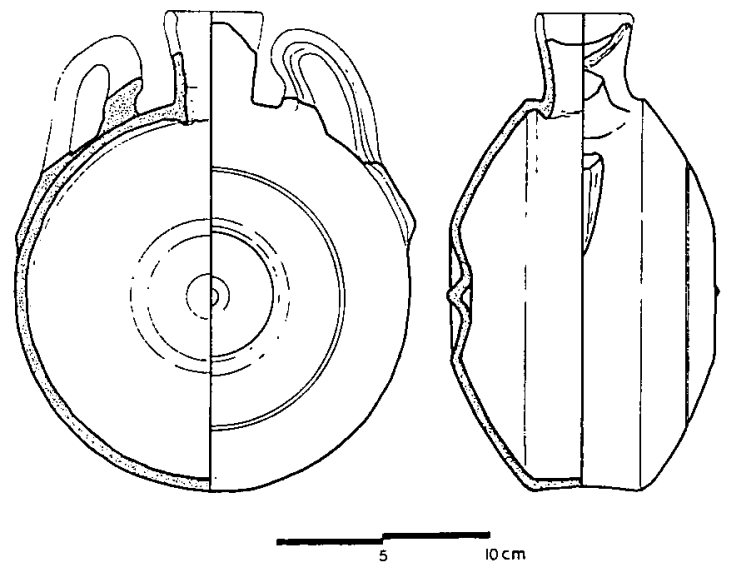

Lám. IV. Fig. 16

ISSN: 1133-4525 ISSN-e: 2255-3924

SPAL 8 (1999)

http://dx.doi.org/10.12795/spal.1999.i8.14 
3

$A E$

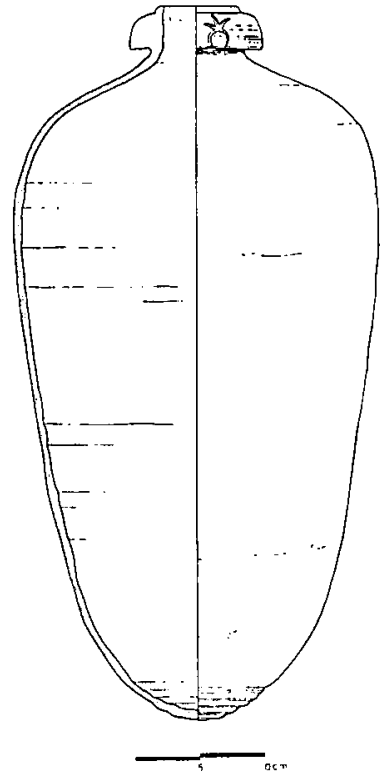

Lám. V. Fig. 17

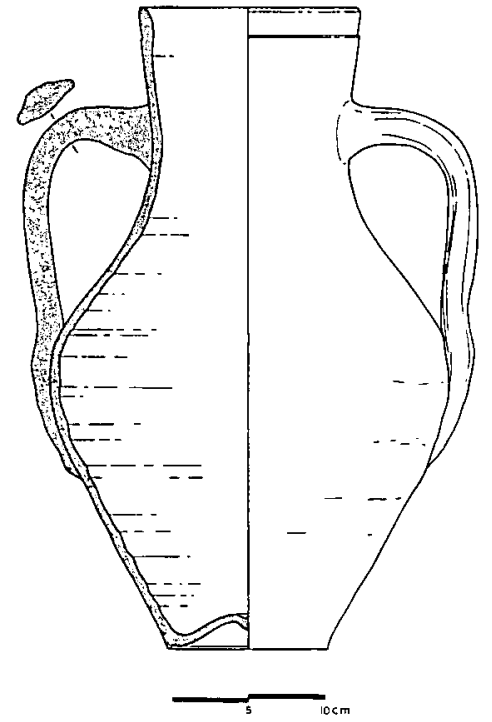

Lám. V. Fig. 21

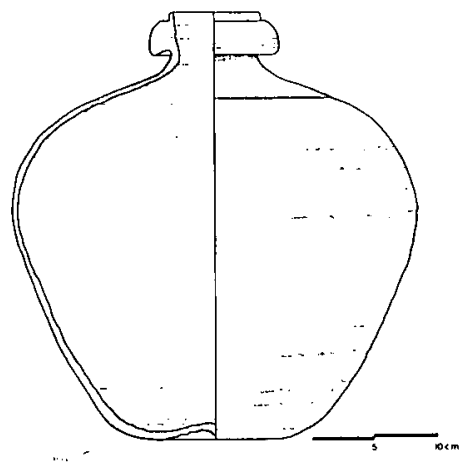

Lám. V. Fig. 18

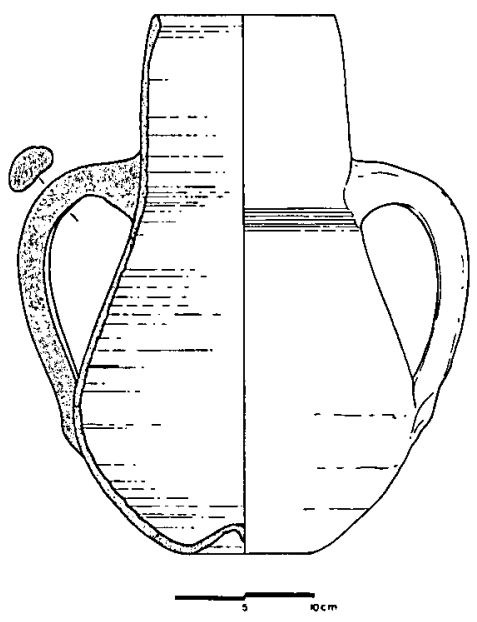

Lám. V. Fig. 20

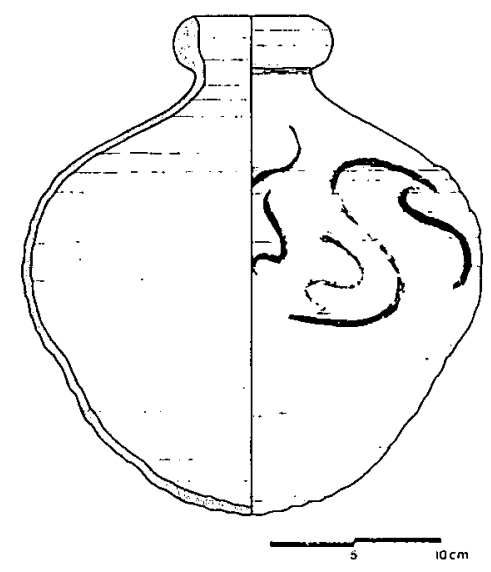

Lám. V. Fig. 19

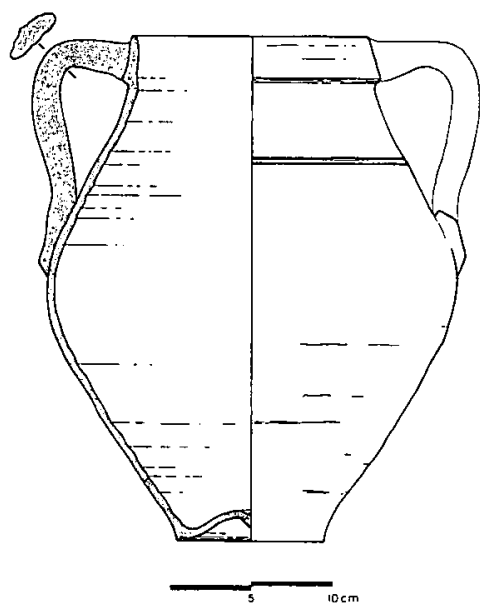

Lám. V. Fig. 22 


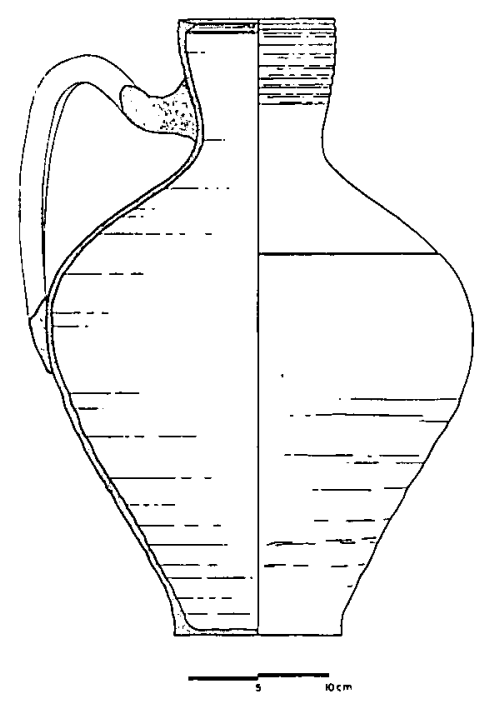

Lám. VI. Fig. 23

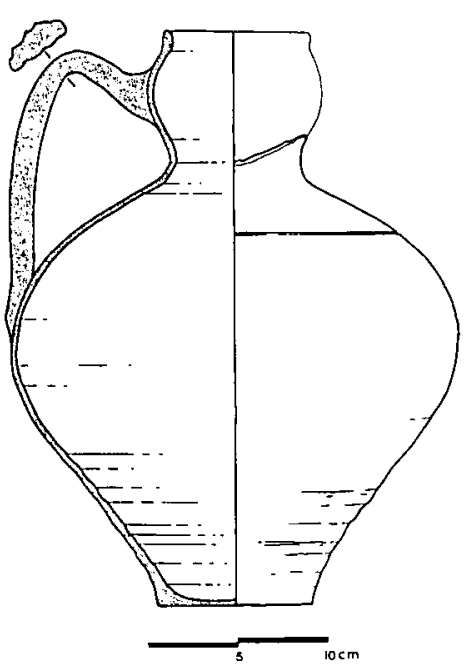

Lám. VI. Fig. 26

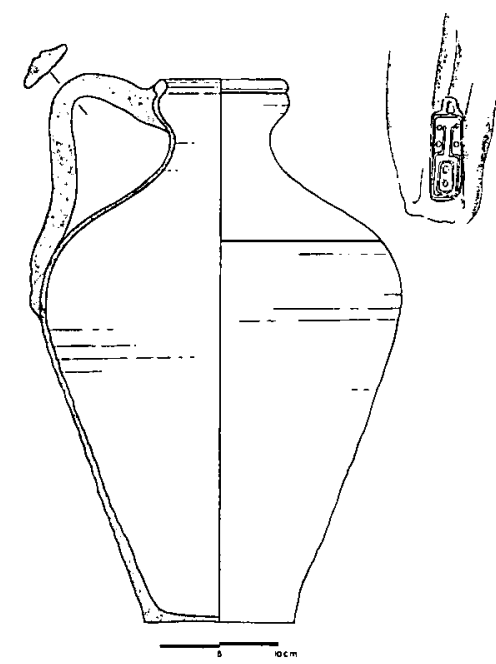

Lám. VI. Fig. 25
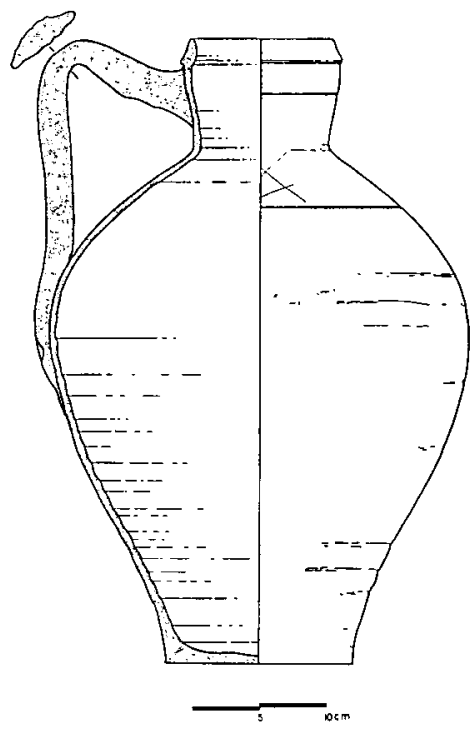

Lám. VI. Fig. 24

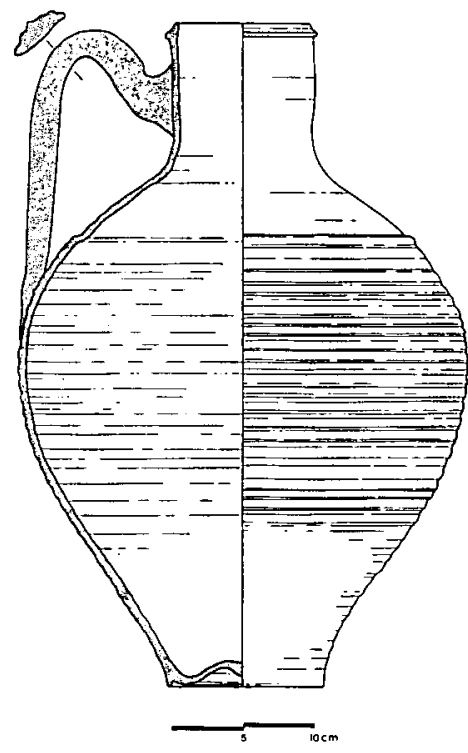

Lám. VI. Fig. 27 


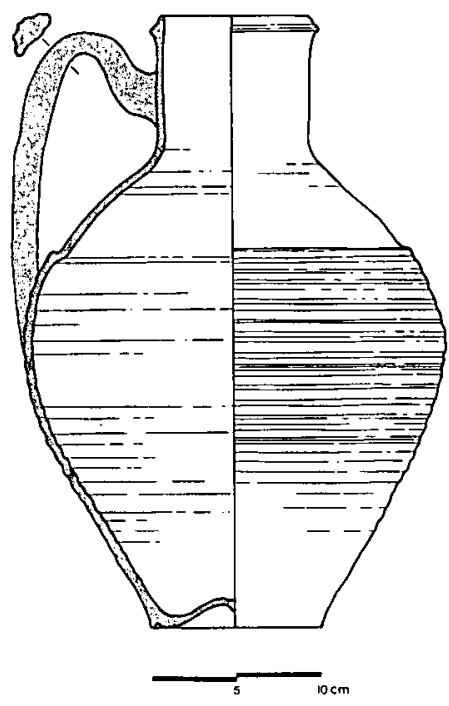

Lám. VII. Fig. 28

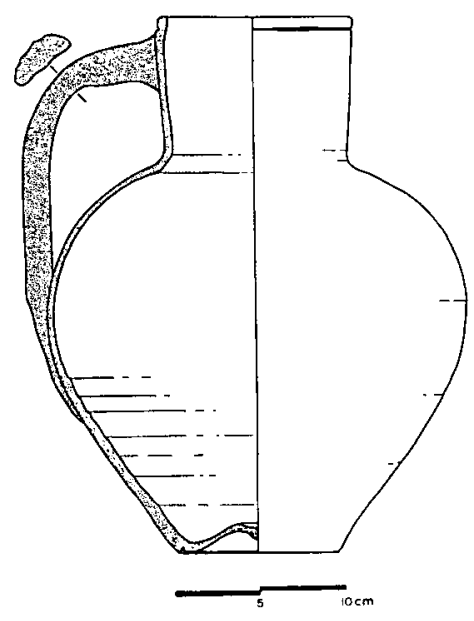

Lám. VII. Fig. 30

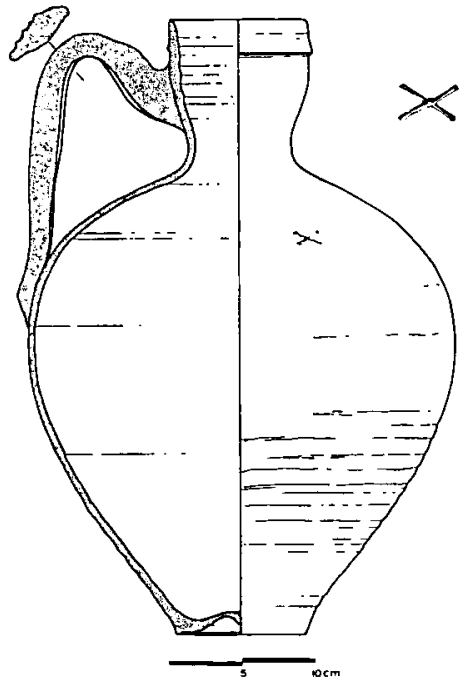

Lám. VII. Fig. 31

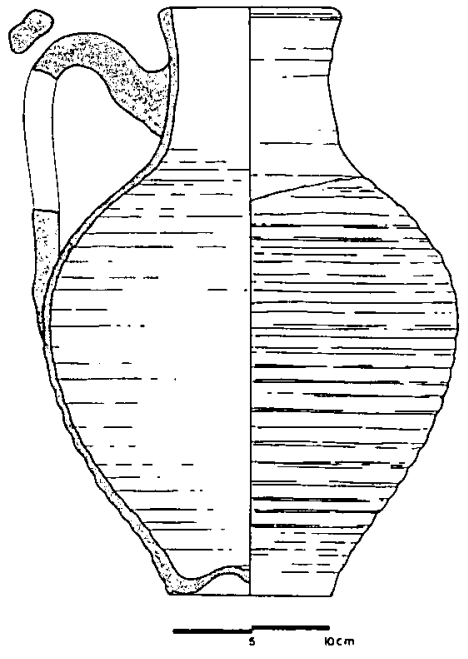

Lám. VII. Fig. 29

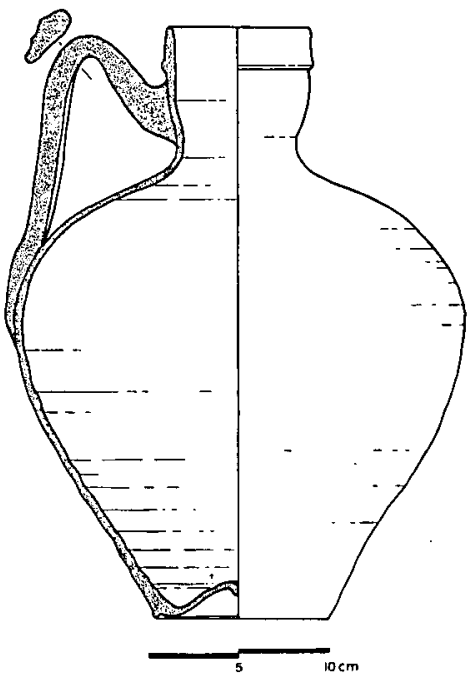

Lám. VII. Fig. 32 


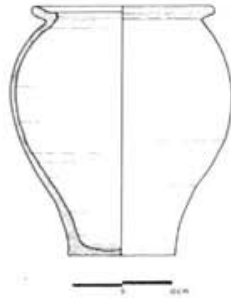

Lám. VIII. Fig. 33

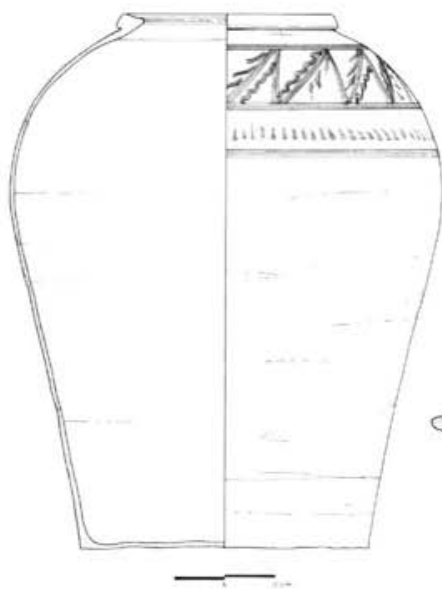

Lám. VIII. Fig. 34

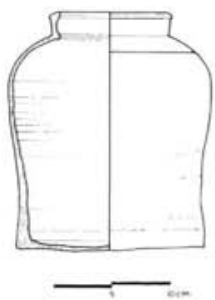

Lám. VIII. Fig. 35

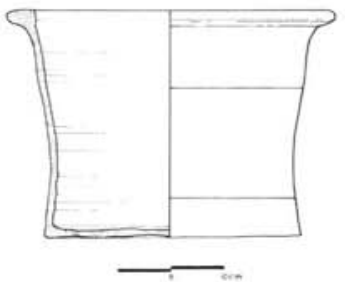

Lám. VIII. Fig. 36

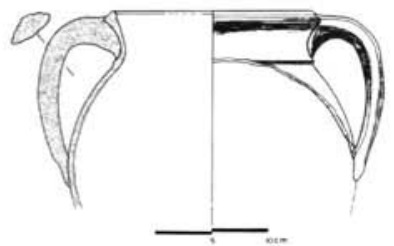

Lám. VIII. Fig. 37

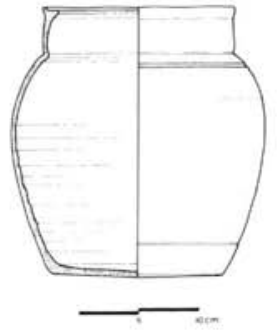

Lám. VIII. Fig. 38

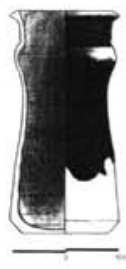

Lám. VIII.

Fig. 39

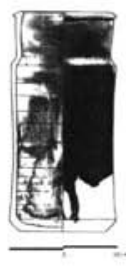

Lám. VIII.

Fig. 40 


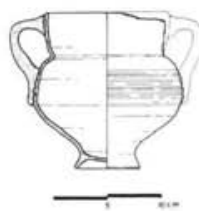

Lám. IX. Fig. 41

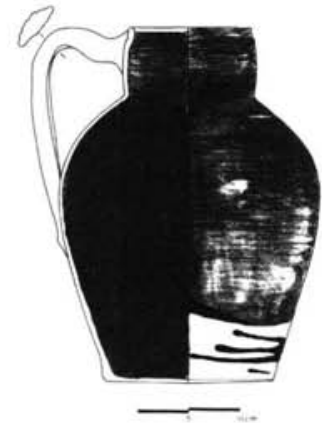

Lám. IX. Fig. 42

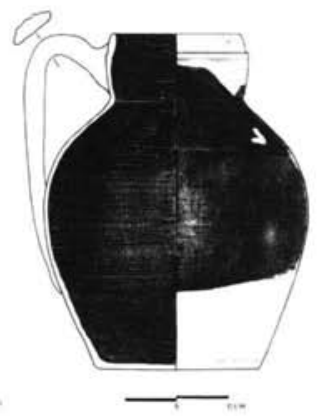

Lám. IX. Fig. 43

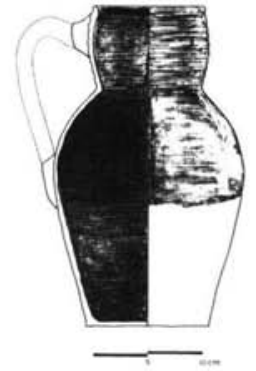

Lám. IX. Fig. 44

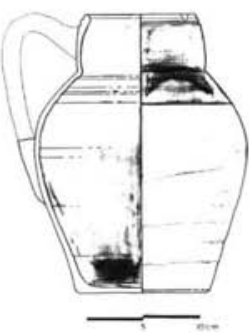

Lám. IX. Fig. 45 


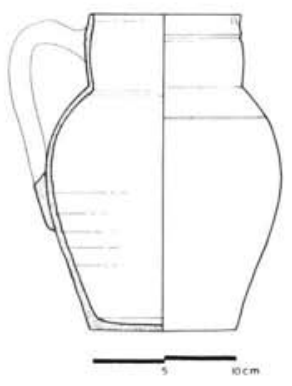

Lám. X. Fig. 46
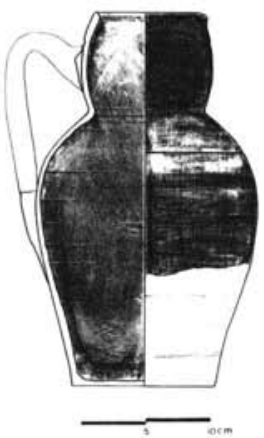

Lám. X. Fig. 49

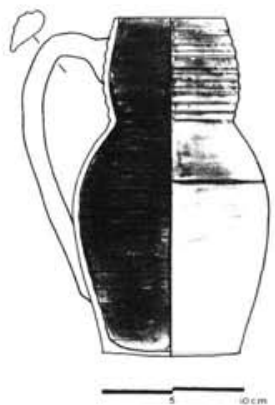

Lám. X. Fig. 47

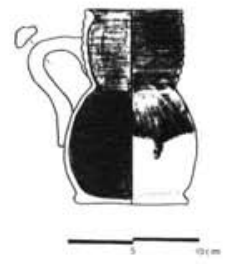

Lám. X. Fig. 50

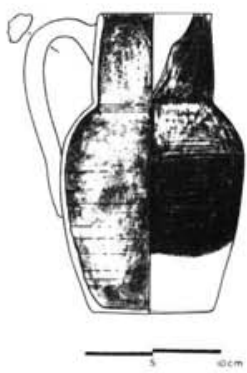

Lám. X. Fig. 48

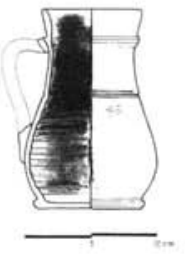

Lám. X. Fig. 51

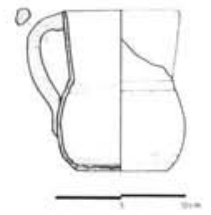

Lám. X. Fig. 52

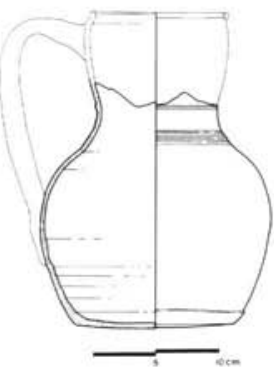

Lám. X. Fig. 53

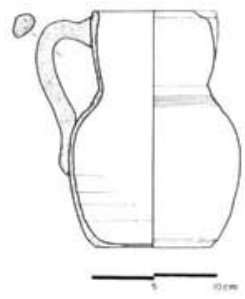

Lám. X. Fig. 54

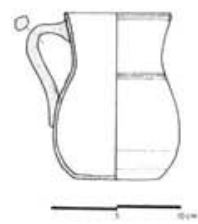

Lâm. X. Fig. 55

ISSN: 1133-4525 ISSN-e: 2255-3924

SPAL 8 (1999) 


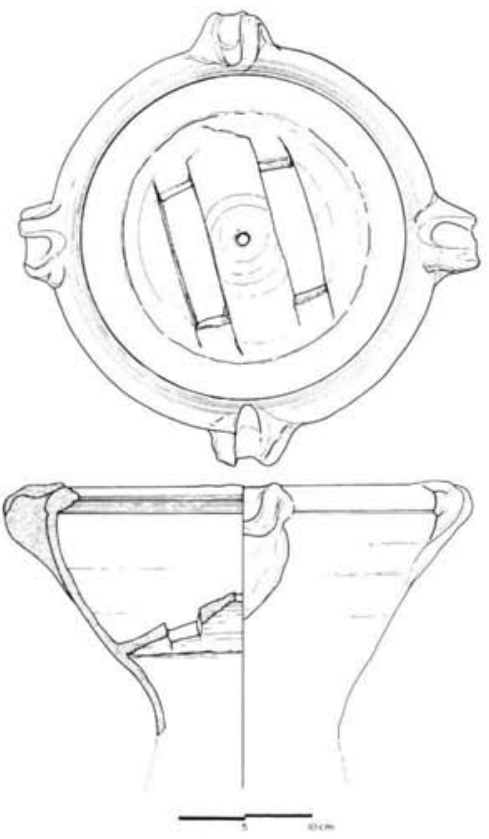

Lám. XI. Fig. 56

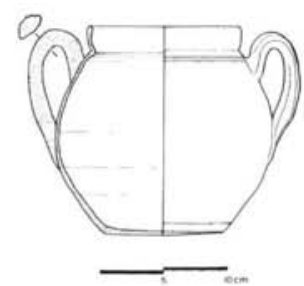

Lám. XI. Fig. 57

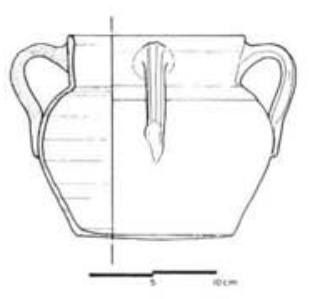

Lám. XI. Fig. 58

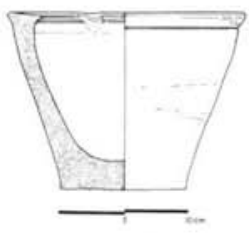

Lám. XI. Fig. 59

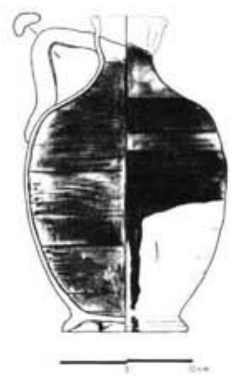

Lám. XI. Fig. 60

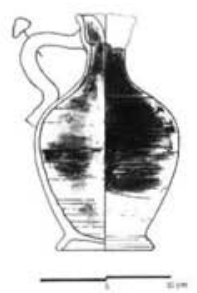

Lám. XI. Fig. 61 


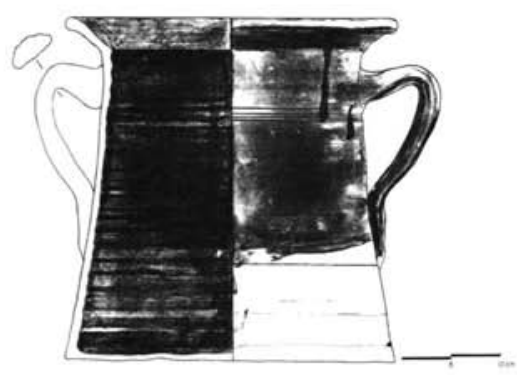

Lám. XII. Fig. 62

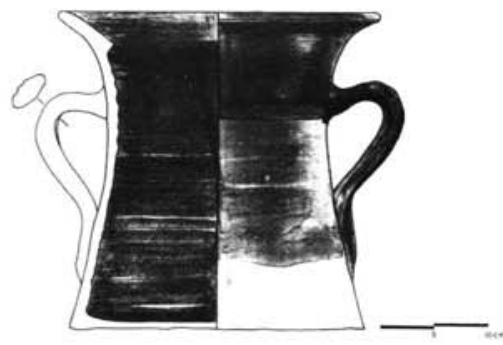

Lám. XII. Fig. 63

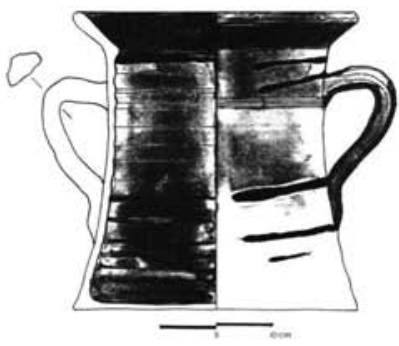

Lám. XII. Fig. 64

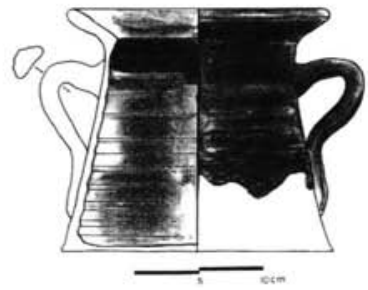

Lám. XII. Fig. 65

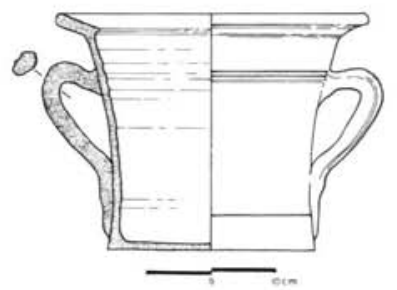

Lám. XII. Fig. 66

ISSN: 1133-4525 ISSN-e: 2255-3924

http://dx.doi.org/10.12795/spal.1999.i8.14

SPAL 8 (1999) 


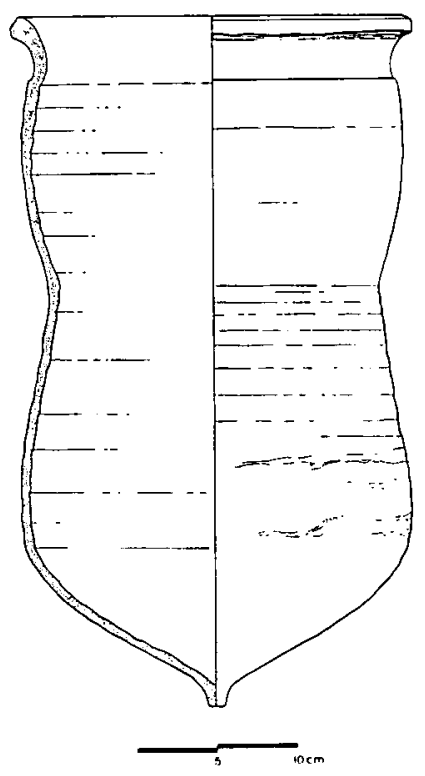

Lám. XIII. Fig. 67

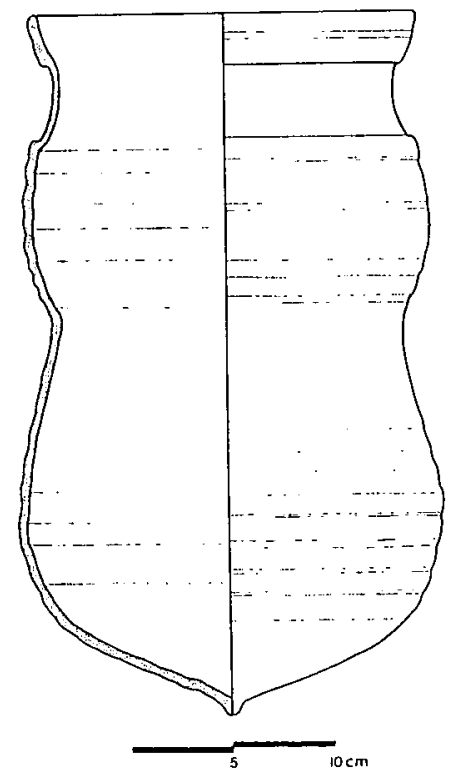

Lám. XIII. Fig. 68

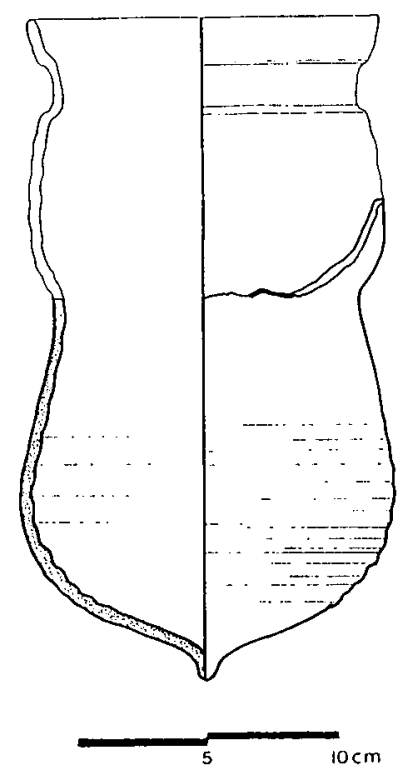

Lám. XIII. Fig. 69

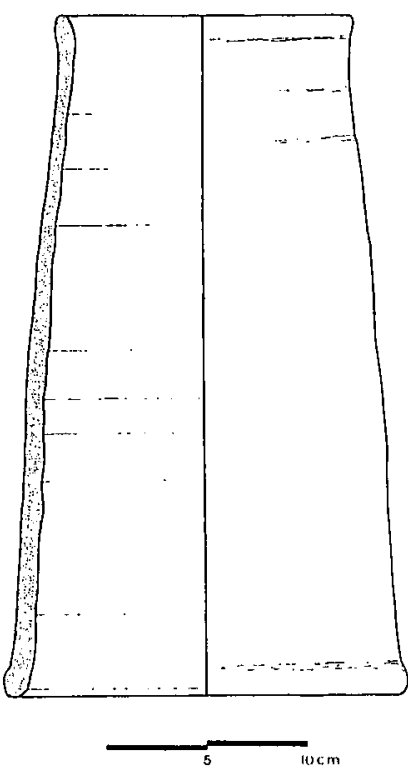

Lám. XIII. Fig. 70

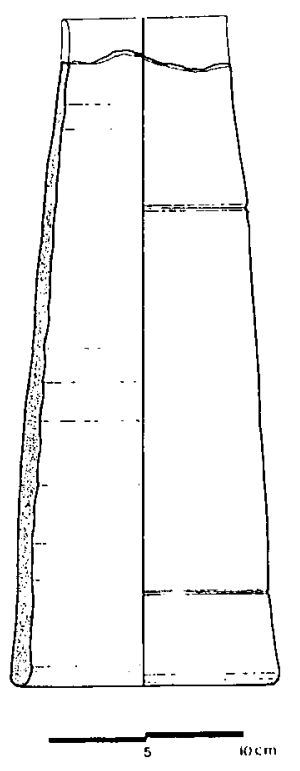

Lám. XIII. Fig. 71

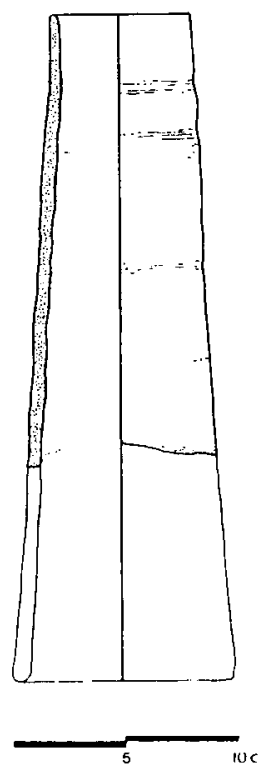

Lám. XIII. Fig. 72

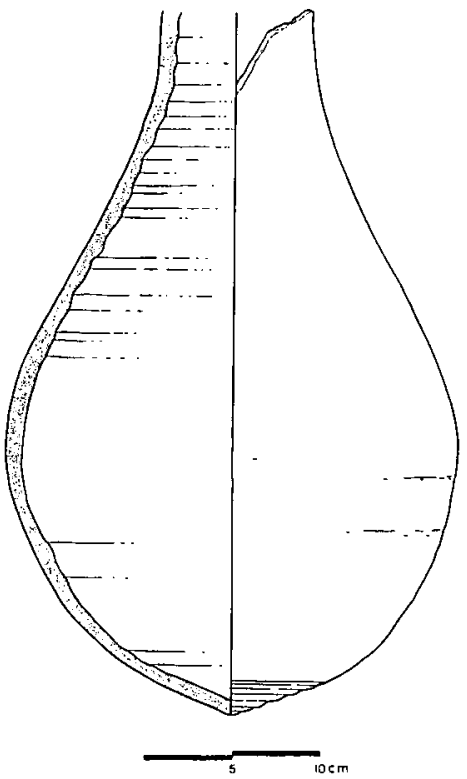

Lám. XIII. Fig. 73 